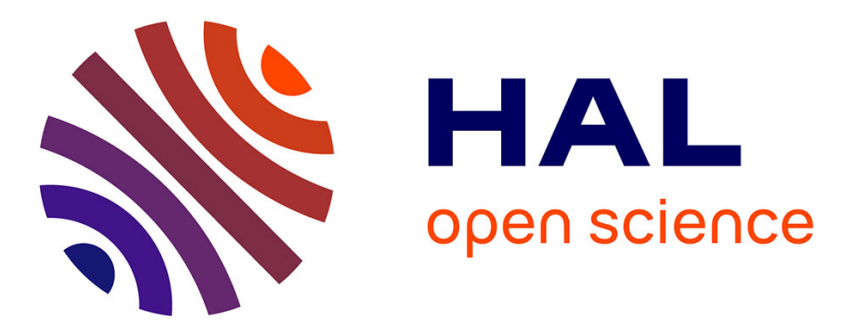

\title{
Turbulent non-uniform flows in straight compound open-channels
}

Sébastien Proust, J.N. Fernandes, Y. Peltier, J.B. Leal, N. Rivière, A.H. Cardoso

\section{- To cite this version:}

Sébastien Proust, J.N. Fernandes, Y. Peltier, J.B. Leal, N. Rivière, et al.. Turbulent non-uniform flows in straight compound open-channels. Journal of Hydraulic Research, 2013, 51 (6), pp.656-667. 10.1080/00221686.2013.818586 . hal-01122551

\section{HAL Id: hal-01122551 \\ https://hal.science/hal-01122551}

Submitted on 4 Mar 2015

HAL is a multi-disciplinary open access archive for the deposit and dissemination of scientific research documents, whether they are published or not. The documents may come from teaching and research institutions in France or abroad, or from public or private research centers.
L'archive ouverte pluridisciplinaire HAL, est destinée au dépôt et à la diffusion de documents scientifiques de niveau recherche, publiés ou non, émanant des établissements d'enseignement et de recherche français ou étrangers, des laboratoires publics ou privés. 
$1 \quad$ Turbulent non-uniform flows in straight compound open-channels

2 SEBASTIEN PROUST (IAHR Member), Research fellow, IRSTEA, UR HHLY, Hydrology-

3 Hydraulics Research Unit, 5 rue de la Doua, 69100 Villeurbanne, France

4 Email: sebastien.proust@irstea.fr (Corresponding Author)

5 JOAO N. FERNANDES (IAHR Member), Ph.D, CEHIDRO and Hydraulics and

6 Environment Department, National Laboratory for Civil Engineering, Lisbon, 1700-066,

7 Portugal

$8 \quad$ Email: jnfernandes@lnec.pt

9 YANN PELTIER (IAHR Member), Ph. D., IRSTEA, UR HHLY, Hydrology-Hydraulics

10 Research Unit, 5 rue de la Doua, 69100 Villeurbanne, France

11 Email: yann.peltier90@gmail.com

12 JOAO B. LEAL (IAHR Member), Research fellow, CEHIDRO and Department of Civil

13 Engineering, Faculdade de Ciencias e Tecnologia, New University of Lisbon, Caparica, 2829-

14 516, Portugal

15 Email: jleal@fct.unl.pt

16 NICOLAS RIVIERE (IAHR Member), Professor, LMFA, Université de Lyon, INSA de 17 Lyon, 20 av. A. Einstein, 69621 France

Email: nicolas.riviere@insa-lyon.fr

19 ANTONIO H. CARDOSO (IAHR Member), Professor, CEHIDRO and DECivil, Instituto

20 Superior Tecnico, Universidade Técnica de Lisboa, Lisbon, 1049-001, Portugal

21 Email: antonio.cardoso@ist.utl.pt 


\begin{abstract}
The reported experimental study assesses the effect of non-uniformity of flow on the momentum flux in straight compound channels. Two flumes were used, featuring vertical and sloping banks. Starting with uniform flow condition, various imbalances in the upstream discharge distribution were introduced. This resulted in a time-averaged lateral flow and an advective transport of momentum, which interacted with the shear-layer turbulence generated by the compound geometry. To investigate this interaction, the three contributions to transverse momentum flux (depth-averaged flow, shear-layer turbulence and dispersive term of spanwise velocity) are assessed. The first two contributions were strengthened by the sloping banks, while the third becomes important for the case of the vertical bank. With a lateral flow towards the main channel, the first contribution rises at the expense of the second. With a lateral flow towards the floodplain, the first two contributions have the same order of magnitude, and the Boussinesq approach is invalidated.
\end{abstract}

Keywords: compound open channel flow; laboratory studies; non-uniform flow; transverse momentum flux; turbulent mixing layers;

\title{
1. Introduction
}

River floods are characterized by overbank flows in compound open-channels. A compound channel consists of a main channel and one or two floodplains. The variation in depth and roughness across the section generates transversally sheared flows. Under uniform flow conditions, these flows are characterized by large-scale, coherent vortices that develop at the boundary between the main channel and the floodplain (herein called sub-sections). These macro-vortices enable the two parallel flows to exchange momentum, affecting the river conveyance (e.g. Sellin 1964, Knight and Shiono 1990, Tominaga and Nezu 1991, Nezu et al. 1999).

Overbank flows are frequently non-uniform. Non-uniformity may be the result of flow unsteadiness, but non-uniform steady flows are also observed in prismatic geometries when (i) a backwater effect is caused by the downstream boundary condition for sub-critical flows or when (ii) the upstream velocity distribution is far from equilibrium. This last flow configuration was considered in the present work to investigate turbulent non-uniform compound channel flows.

The motivation for this study stems from the fact that a change in cross-sectional shape, bottom slope and/or roughness occurs upstream from a prismatic reach, which necessarily leads to an upstream imbalance in the velocity distribution between the subsections. Three examples of flow configurations observed in natural streams are shown in Fig. 1: (a) diverging or (b) converging floodplains upstream from a prismatic reach; and (c) prismatic reach with a longitudinal transition in the hydraulic roughness on the floodplains. The flow deficit that was observed over diverging floodplains by Bousmar et al. (2006) leads to a flow redistribution from the main channel towards the floodplain along the prismatic reach. By contrast, the flow excess on converging floodplains (Bousmar et al. 2004 and Proust et al.2006) results in a decelerating flow over the floodplains of the prismatic reach. 
The third example is inspired by Vermaas et al. (2011), who experimentally studied the influence of a lateral increase in hydraulic roughness on an initially uniform flow in a single channel. A lateral mass exchange was observed from the decelerating flow over the rougher bed to the accelerating flow over the smoother bed. With a similar lateral change in roughness across a compound geometry, the third case shown in Fig. 1(c) features a lateral flow towards the main channel.

Bousmar et al. (2005) was one of the first studies dealing with steady flows in prismatic compound channels with an upstream imbalance in the velocity distribution. The streamwise evolution of the discharge distribution between the sub-sections was examined in three laboratory flumes. The lateral mass exchange was found to be a slow process acting on longitudinal distances ranging from $8 \times B_{f}$ to $35 \times B_{f}$ ( $B_{f}$ being the width of one floodplain). Using the same data, Proust et al. (2010) focused on the energy losses and showed that the streamwise profile of the total head was different from one sub-section to another.

In the two previously mentioned works, the turbulent quantities were not measured. In the present work, we investigated the interaction between the time-averaged transverse flow caused by the longitudinal non-uniformity and the shear-layer turbulence generated by the compound geometry. We estimated the three contributions to transverse momentum flux, namely the depth-averaged lateral Reynolds shear stress, a dispersive term of spanwise velocity over the depth, and the momentum flux by the depth-averaged velocity components. Specific attention was given to the vertical interface between the sub-sections, since it plays an important role in 1D (Bousmar and Zech 1999) or 1D+ numerical modelling (Proust et al. 2009, 2010). In particular, the validity of the Boussinesq approach is analysed.

The experiments were carried out in two flumes, presenting vertical and sloping banks. These two different geometries enable the assessment of the effect of the bank slope on the mass and momentum exchanges. Each data set is composed of a uniform flow and nonuniform flow cases, which are produced by an imbalance in the upstream discharges. An excess or a deficit in floodplain inflow were both investigated.

\section{Experimental procedure}

\subsection{The two laboratory flumes}

The experiments were performed in two compound channel flumes located at the Laboratory of Fluid Mechanics and Acoustics (LMFA), Lyon, France, and at the National Laboratory of Civil Engineering (LNEC), Lisbon, Portugal. The schematic top views and cross-sections of the flumes are shown in Fig. 2. The LMFA flume is $8 \mathrm{~m}$ long, $1.2 \mathrm{~m}$ wide, and is made of PVC with a bottom slope of $1.8 \mathrm{~mm} / \mathrm{m}$. The cross-section was asymmetrical, composed of a rectangular main channel and a floodplain, with a bank full height, $h_{b}$, of 
$53 \mathrm{~mm}$. The LNEC flume is $10 \mathrm{~m}$ long, $2 \mathrm{~m}$ wide, and made of polished concrete with a bottom slope of $1.1 \mathrm{~mm} / \mathrm{m}$. The symmetrical cross-section was composed of two floodplains and one trapezoidal main channel with a bank slope of $45^{\circ}$ and a height, $h_{b}$, of $100 \mathrm{~mm}$. The Manning roughness was $0.0091 \mathrm{~m}^{-1 / 3} / \mathrm{s}$ and $0.0092 \mathrm{~m}^{-1 / 3} / \mathrm{s}$, at LMFA and LNEC, respectively. These values were obtained by isolating one sub-section from another with a moveable vertical wall.

Following the recommendations of Bousmar et al. (2005), independent inlets for the main channel and for the floodplains were used in both flumes (see Fig. 2), and the discharges were measured with independent electromagnetic flow meters (uncertainty of $0.2 \mathrm{~L} / \mathrm{s}$ to $0.3 \mathrm{~L} / \mathrm{s}$ ). To adjust water levels, independent downstream tailgates (one per sub-section) were used in each flume.

A Cartesian coordinate system is used in which $x, y$ and $z$ refer to the longitudinal, lateral and vertical directions, respectively (see Fig. 2), and $u, v, w$ refer to the components of instantaneous velocity. The system origin is defined as: $x=0$ at the inlet cross-section; $y=0$ at the sidewall of the right-hand floodplain; and at a given $x$ station, elevation $z$ is measured from the bed of the main channel.

\subsection{Measurement of velocity and water level}

In both flumes, velocity was measured with a $10 \mathrm{MHz}$ micro ADV (Vectrino+), equipped with a two-dimensional side-looking probe. The sampling volume was a $7 \mathrm{~mm}$ long cylinder with $6 \mathrm{~mm}$ diameter. The acquisition time was $3 \mathrm{~min}$ at each measurement position, with a sampling rate of $100 \mathrm{~Hz}$. With 18,000 samples, the convergence of first and second statistical moments of the velocity components was ensured and the error on Reynolds shear stress is expected to be $\pm 3 \%$ according to Chanson et al. (2007). The flow was seeded with $10 \mu \mathrm{m}$ hollow glass spheres to get a signal-to-noise ratio higher than $20 \mathrm{~dB}$ as recommended by McLelland and Nicholas (2000). The ADV data were despiked using the phase-space thresholding technique of Goring and Nikora (2002), and correlations lower than 70\% were excluded from the time-series.

To correct errors of misalignment of the ADV probe with respect to the longitudinal direction, the pitch angle was slightly modified during the post-processing. A single correction angle was used for each measured cross-section. At LMFA, the depth-averaged spanwise velocity, $V_{d}$, was assumed to be zero in the measuring volume that was nearest the main channel sidewall (5 $\mathrm{mm}$ from the wall). At LNEC, the value of $V_{d}$ was minimized both on the main channel centreline and at the last measured position that was located $50 \mathrm{~mm}$ from the floodplain sidewall. The correction angle is in the range $\pm 0.5^{\circ}$ in both flumes, and it was 
accounted for when computing local time-averaged velocity and Reynolds stresses, as recommended by Roy et al. (1996) and Peltier et al. (2013b).

The measuring cross-sections were located at downstream distances $x=2.5,4.5$ and $6.5 \mathrm{~m}$ at LMFA, and at $x=1.1,3.0,5.0$ and $7.5 \mathrm{~m}$ at LNEC. The velocity measuring grids are shown in Fig. 2, with 43 to 45 lateral positions and with up to 10 vertical positions (interface between the sub-sections). At LMFA, velocity was also measured at $x=5.5 \mathrm{~m}$ at floodplain edge. In both flumes, the flow rate computed from the integration of the velocity field was within 97 to $100 \%$ of the values measured by the flow meters.

Water levels were measured with an ultrasonic sensor (uncertainty of $\pm 0.2 \mathrm{~mm}$ ) at LMFA, and with a point gauge (uncertainty of $\pm 0.3 \mathrm{~mm}$ ) at LNEC.

\subsection{Flow conditions}

Uniform flow conditions were used as a reference situation. In both flumes, the relative flow depth, $D_{r}=h_{f} / h_{m}$, was chosen to be 0.3. As shown in Fig. $2, h_{f}$ is the mean flow depth on the floodplain and $h_{m}$ is the mean flow depth in the main channel (outside the sidesloped region at LNEC). The flow is considered uniform when both the flow depth and the depth-averaged streamwise velocity, $U_{d}$, are constant along $x$-direction (see sections 4.1 and 4.4). To obtain a constant flow depth all along the flume, both the height of the downstream tailgates and the upstream discharge distribution were adjusted. Then, the uniform flow was disturbed by varying the upstream discharges, but keeping the total flow rate and the height of the tailgates unchanged. Let us consider the variation in the floodplain discharge, $Q_{f}$, with respect to uniform flow conditions:

$$
\Delta Q_{f}(x)=\frac{Q_{f}(x)-Q_{f}^{u}(x)}{Q_{f}^{u}(x)} \times 100
$$

where superscript $u$ refers to uniform flow. The inflow conditions, which are defined by $\Delta Q_{f}(x=0)$, are reported in the first column in Table 1 . The total flow rate $Q$ is $27.4 \mathrm{~L} / \mathrm{s}$ and 80.6 L/s, at LMFA and LNEC, respectively. For each flow rate $Q$, two or three excesses and one deficit in floodplains inflow were investigated $(+19 \%,+38 \%,+53 \%$ and $-19 \%)$.

To compare the non-uniform flows at position $x$ with the uniform flow of same total discharge, $Q$, a non-uniformity parameter, $N$, was defined as:

$$
N(x)=\frac{U_{m}(x)-U_{f}(x)}{U_{m}^{u}(x)-U_{f}^{u}(x)}
$$


where $U_{m}$ and $U_{f}$ are the mean velocities in the main channel and floodplain, respectively. A time-averaged transverse flow from the floodplain to the main channel implies that $N<1$.

The values of parameters $N, D_{r}, U_{f}$, $U_{m}$, and $h_{f}$, which were measured in the most upstream measuring section, are also shown in Table 1 . The cases $+53 \%$ at LMFA and $+38 \%$ at LNEC feature a small or nil upstream velocity difference, $U_{m}-U_{f}$, as observed at the outlet of an abrupt contraction of the floodplain by Proust et al. (2006). The deficit of $-19 \%$ corresponds to flow conditions at the outlet of a diverging compound channel (see Fig. 1). This table also presents the Froude numbers in the sub-sections, $\mathrm{F}_{f}$, and $\mathrm{F}_{m},\left(\mathrm{~F}_{i}=U_{i} / \sqrt{g R_{i}}\right.$, where $i=m$ or $f$, and $R_{i}$ is the hydraulic radius in one sub-section). Regarding the Reynolds numbers in a sub-section $\left(\mathrm{R}_{\mathrm{i}}=4 U_{i} R_{i} / v\right.$, with $v=$ kinematic viscosity $)$, $\left.\mathrm{R}_{\mathrm{f}} \in 6 \times 10^{4}-1.1 \times 10^{5}\right]$, and $\mathrm{R}_{\mathrm{m}} \in\left[2.4 \times 10^{5}-3.4 \times 10^{5}\right] \quad$ at LNEC, and $\mathrm{R}_{\mathrm{f}} \in\left[2.5 \times 10^{4}-4.2 \times 10^{4}\right], \mathrm{R}_{\mathrm{m}} \in\left[1.2 \times 10^{5}-1.6 \times 10^{5}\right]$ at LMFA. Considering the equivalent sand roughness, $k_{s}$, in both flumes $\left(1.5 \times 10^{-6} \mathrm{~mm}\right.$ at LMFA, and $1.5 \times 10^{-4} \mathrm{~mm}$ at LNEC), all flow cases in both sub-sections are hydraulically smooth at LMFA, or transitional flow at LNEC, according to the corrected Moody diagram (French 1985).

\section{Theoretical background}

\subsection{Lateral exchange of streamwise momentum}

Under uniform flow conditions, an important issue is to identify the contributions of turbulent diffusion and of secondary flows to the transverse momentum flux (see e.g. Shiono and Knight 1991, van Prooijen et al. 2005, Kara et al. 2012). Under non-uniform flow conditions, another source of transverse momentum flux has to be taken into account, i.e. the advective transport of momentum by the bulk flow. In the present paper, these three contributions to the lateral exchange of streamwise momentum were accounted for using a depth-averaged approach.

The time average of the depth-averaged lateral exchange of streamwise momentum yields:

$$
\overline{1 / h \int_{0}^{h}-\rho u v d z}=-1 / h \int_{0}^{h} \rho \overline{u^{\prime} v^{\prime}} d z-1 / h \int_{0}^{h} \rho \overline{u v} d z
$$

where $h$ is the local flow depth, $\left({ }^{-}\right)$the time-averaging operator, $\rho$, the fluid density, $u$ and $v$, the instantaneous longitudinal and lateral velocities, $\bar{u}$ and $\bar{v}$, the time-averaged longitudinal and lateral velocities, and $u^{\prime}$ and $v^{\prime}$, the fluctuations of the velocity components about the averaged values. 
The first term on the right-hand side of Eq. (3) is the depth-averaged lateral Reynolds shear stress, denoted $T_{x y}$ :

$$
T_{x y}=1 / h \int_{0}^{h}-\rho \overline{u^{\prime} v^{\prime}} d z
$$

The second term on the right-hand side of Eq. (3) is the lateral exchange of streamwise momentum by the time-averaged flow, denoted $M_{x y}$ :

$$
M_{x y}=-1 / h \int_{0}^{h} \rho \overline{u v} d z=-\rho U_{d} V_{d}-1 / h \int_{0}^{h} \rho \bar{u}\left(\bar{v}-V_{d}\right) d z
$$

where $U_{d}$ and $V_{d}$ are the depth-averaged, time-averaged longitudinal and lateral velocity.

According to Eq. (5), the term $M_{x y}$ is the sum of the advective transport of momentum by the depth-averaged flow and of a dispersive term of spanwise velocity $\bar{v}$ over the depth, denoted $-\left.\rho \bar{u}\left(\bar{v}-V_{d}\right)\right|_{d}$ in the following. Under uniform flow conditions, the velocity $V_{d}$ is nil, but the depth-averaged value of $\overline{u v}$ can be different from zero due to secondary currents.

\subsection{The Boussinesq approach}

The Boussinesq assumption was validated for uniform compound channel flows, e.g. by Shiono and Knight (1991) or van Prooijen et al. (2005). If gradients $\partial V_{d} / \partial x$ and $\partial \bar{v} / \partial x$ are negligible compared to $\partial U_{d} / \partial y$ and $\partial \bar{u} / \partial y$, respectively, a local transverse eddy viscosity, $\varepsilon_{x y}$, and a depth-averaged transverse eddy viscosity, $\left.\varepsilon_{x y}\right|_{d}$ can be defined as:

$$
\begin{gathered}
-\overline{u^{\prime} v^{\prime}}=\varepsilon_{x y} \frac{\partial \bar{u}}{\partial y} \\
T_{x y} / \rho=\left.\varepsilon_{x y}\right|_{d} \frac{\partial U_{d}}{\partial y}
\end{gathered}
$$

We will also investigate in this paper, if the Boussinesq approach is still relevant when the flow is non-uniform.

\section{Results}

\subsection{Relative flow depth}

The longitudinal variation in relative flow depth, $D_{r}$, is shown in Fig. 3(a) for the various floodplain inflows $\Delta Q_{f}(x=0)$. The relative flow depth is constant along both 
217 flumes when the flow is uniform. The analysis of non-uniform flows shows that the cases

218 with an excess in the floodplains inflow tend towards the uniform relative flow depth more

219 rapidly than the cases with a deficit in the floodplains inflow. Considering runs $+19 \%$ and

$220-19 \%$ that are symmetric in terms of floodplains inflow relative to uniform flow, the profile

221 of $D_{r}$ for run $-19 \%$ is further from the uniform flow profile along the two flumes.

222 Figure 3(a) also shows that the relative flow depth, $D_{r}$, increases from run $-19 \%$ to

223 run $+53 \%$, i.e. when the velocity difference between the sub-sections, $U_{m}-U_{f}$, decreases. The

224 largest variation in $D_{r}$ was observed in the first measuring section: the discrepancy from uniform relative flow depth ranges from $-4 \%$ to $+8 \%$ at LNEC, and from $-6 \%$ to $+8 \%$ at LMFA (see data of $D_{r}$ in Table 1).

\subsection{Velocity difference between sub-sections}

Figure 3(b) shows the longitudinal variation in the non-uniformity parameter, $N$ (see Eq. (2)). The $N$-profiles prove that a time-averaged transverse flow occurs between the subsections until the most downstream measuring section for each non-uniform case in both flumes. The length of the flumes is not sufficient so that any of the non-uniform cases reaches equilibrium $(N=1)$.

Figures 3(a) and 3(b) show that the relative flow depth, $D_{r}$, tends to equilibrium more rapidly than the $N$-parameter. In the LNEC flume at $x / B_{f}=10.7$, the discrepancy from uniform relative flow depth ranges from $-2 \%$ to $+1 \%$, while the parameter $N$ significantly varies from 0.49 to 1.25 . When using dimensional variables, this means that several velocity differences between the sub-sections can be obtained with the same flow depth. In accordance with Bousmar et al. (2005), this shows that using constant water depth as the unique criterion of flow uniformity can lead to erroneous results.

\subsection{Depth-averaged transverse flow}

The lateral distribution of time-averaged and depth-averaged spanwise velocity, $V_{d}$, is shown in Fig. 4 at $x / B_{f}=5.6$ and 4.3 at LMFA and LNEC, respectively. This velocity is scaled by the bulk velocity under uniform flow conditions, $U_{A}^{u}=Q / A^{u}$. When the flow is non-uniform, the transverse flow is not laterally uniform. In both flumes, the highest values of $\left|V_{d}\right|$ are observed on the floodplains near the vertical interface between sub-sections, and irrespective of the $N$-parameter. Beyond $y / B_{f}=1,\left|V_{d}\right|$ decreases in the main channel. At LMFA, this decrease is sharp owing to low values of local spanwise velocity, $\bar{v}$, below the bank full height, $h_{b}$. At LNEC, the sloping bank ensures a smoother decrease in $\left|V_{d}\right|$ between the top and the bottom of the bank. 


\subsection{Mixing layer width}

The depth-averaged streamwise velocity, $U_{d}$, is shown in Fig. 5 in the most downstream measuring sections. At LMFA, a local decrease is observed near the centreline position in the main channel, irrespective of the direction and magnitude of the transverse flow. This decrease is the result of marked counter-rotating secondary flows that will be analysed further in section 4.5 .

Let us consider a moving average with three consecutive values of $U_{d}$, such that the changes in this average are lower than $1 \mathrm{~cm} / \mathrm{s}$ (uncertainty on velocity measurement). We can define two local plateaux of $U_{d}$, and two associated velocities $U_{d l}$ and $U_{d 2}$, which are located out of the shear-layer on the floodplain and in the main channel, respectively (shown in Fig. 5 for $N>1$ ). In LMFA, $U_{d 2}$ is, therefore, located on the left-hand side of the local decrease in velocity.

Similarly to Pope (2000) for unbounded mixing layers, we can define the lateral location $y_{\alpha}(x)$ for $0<\alpha<1$ such that depth-averaged velocity, $U_{d}$, can be defined as:

$$
U_{d}\left(x, y_{\alpha}(x)\right)=U_{d 1}+\alpha\left(U_{d 2}-U_{d l}\right)
$$

and consider a characteristic width of the mixing layer $\delta(x)$ as

$$
\delta(x)=y_{0.9}(x)-y_{0.1}(x)
$$

with $y_{\alpha}=0$ at the sidewall of the right-hand floodplain (see Fig. 2)

The longitudinal variations in the scaled width, $\delta / B_{f}$, and the scaled position, $y_{0.1} / B_{f}$, are shown in Fig. 6 for seven flow cases. Additional values of $\delta$ are displayed for the uniform flow at LMFA (nine measuring sections). They were obtained from $U_{d}$-profiles that were measured by Peltier et al. (2013a) with identical flow conditions in the same flume. With the uniform flows in Fig. 6(a), after a phase of growth along the $x$-direction, the width of the mixing layer $\delta$ reaches a constant value at $x / B_{f}=5.6$ and 4.3 , at LMFA and LNEC, respectively. Beyond these two downstream positions: (i) the mixing layer is self-sustained owing to the topographical forcing of the 2-stage channel (Jirka 2001); and (ii) the flow can rigorously be considered as uniform since no significant transverse flow occurs across the flumes (see Fig. 4).

It can be seen in Fig. 6(b) that for cases with an excess in floodplain flow, the lateral boundary of the mixing layer, $y_{0.1}$, is increasingly moved towards the main channel with an increase in the floodplain inflow. The high spanwise velocities near $y / B_{f}=1$ on floodplain side (see Fig. 4) are responsible for the displacement of the shear layer. With case $+53 \%$ at LMFA or case $+38 \%$ at LNEC, the lateral position, $y_{0.1}$, is displaced into the main channel until the most downstream measuring section. As shown in Fig. 6(a), this results in a 
significant decrease in the mixing layer width, $\delta$, relative to uniform flow case. The lateral displacement of the layer is constrained by the presence of the main channel sidewall at LMFA or the symmetry axis at LNEC, and by the high speed flow in the main channel of both flumes. For example, with the case $+19 \%$ at LMFA, the flow that is the closest to equilibrium $\left(N=0.88\right.$ at $x / B_{f}=8.1$ in Fig. 3(b)), a $30 \%$ decrease is observed relative to the mixing layer width of the uniform flow.

With cases $-19 \%$, the mixing layer in both flumes laterally spreads onto the floodplains in the downstream direction (see $y_{0.1}$ in Fig. 6(b)), with a linear evolution.

These changes in the lateral position, $y_{0.1}$ and the mixing layer width were also observed by Peltier et al. (2013a) in the LMFA flume with a transverse embankment set on the floodplain. With the same total flow rate $Q=24.7 \mathrm{~L} / \mathrm{s}$, and with a $50 \mathrm{~cm}$-long embankment, the width $\delta$ is zero close to the embankment owing to very large transverse flows.

\subsection{Time-averaged streamwise velocity}

Under uniform flow conditions, preliminary measurements of the vertical profiles of the time-averaged streamwise velocity $\bar{u}$ were carried out along the centreline position in the main channel, every $\Delta x=0.5 \mathrm{~m}$ or $1 \mathrm{~m}$. The vertical distribution of $\bar{u}$ stops evolving from downstream positions $x / B_{f}=6.8$ at LMFA, and 8.6 at LNEC flume, with a log-law in the inner region. Figure 7 shows the cross-sectional distribution of $\bar{u}$, scaled by $U_{A}^{u}$, in the last measuring sections, at $x / B_{f}=8.1$ and 10.7, at LMFA and LNEC, respectively. In the main channel of LMFA flume, the presence of two counter-rotating secondary flows can be inferred from the inflection of the contours of velocity $\bar{u}$, upwards near the centreline position and downwards in the corners. In the results from LNEC, the presence of secondary flows is not so clear, despite of a similar aspect ratio $B_{m} / h_{b}$. As stated by Ikeda and McEwan (2009) for uniform flows, the presence of a vertical bank and a vertical sidewall strengthen secondary currents in comparison to the sloping banks of the LNEC flume. The present data set shows the maintenance of secondary currents cells when the flow is gradually varied. However, Fig. 7(a) and Fig. 5 (top plot) show that the region of local deficit in velocity is shifted towards the main channel sidewall by a mass transfer coming from the floodplain, i.e. for $N<1$. Comparing cases $N=1$ and $N=0.64$, the local decrease in velocity $U_{d}$ in Fig. 5 (top plots) is displaced from $y / B_{f}=1.2$ to 1.25 , i.e. of $4 \mathrm{~cm}$ ( $10 \%$ of the main channel width).

In both flumes, in spite of the wide range of variation in the non-uniformity parameter $N$, the general pattern of primary velocity $\bar{u}$ is weakly affected by the transverse flow in the most downstream measuring section. However, some local changes can be observed close to the interface between sub-sections. At LNEC, near $y / B_{f}=1$, the contours of $\bar{u}$ for the cases 
$-19 \%$ and $+38 \%$ clearly differ, depending on the direction of the transverse flow. At LMFA, the contours of $\bar{u}$ near the floodplain edge in the main channel are inclined where the floodplain flow gets into the faster flow (compare $N=1$ to $N=0.64$ )

\subsection{Lateral Reynolds shear stress}

Figure 8 shows the lateral distribution of depth-averaged lateral Reynolds shear stress, $T_{x y}$, at $x / B_{f}=[8.1,10.7]$, at LMFA and LNEC, respectively. Comparing Fig. 8 to Fig. 5 indicates, at least from a qualitative point of view, a link between the lateral distributions of $T_{x y}$ and of the streamwise velocity $U_{d}$. The shear layer turbulence appears to be locally induced by the streamwise velocity field. The Boussinesq assumption, which was validated for uniform compound channel flows, could still be valid for non-uniform flows in both flumes. The link between $T_{x y}$ and lateral gradient $\partial U_{d} / \partial y$ is clear, irrespective of the $N$-value. For $N<1$, the shear stress $T_{x y}$ is negligible as velocity $U_{d}$ is constant across the whole floodplain. For $N>1$, the region of high shear stress $T_{x y}$ coincides with the region of high gradients $\partial U_{d} / \partial y$, between $y / B_{f}=0.7$ and 1.0 in both flumes. In addition, the negative values of gradient $\partial U_{d} / \partial y$ that are related to the secondary currents and to the sidewall effect in the main channel at LMFA lead to negative values of $T_{x y}$.

Figure 9 shows the cross-sectional distribution of lateral Reynolds shear stress $-\rho \overline{u^{\prime} v^{\prime}}$, scaled by $\rho\left(U_{m}-U_{f}\right)^{2}$, as the velocity difference $U_{m}-U_{f}$ is the natural source of the shear-layer turbulence. All cases feature a marked 2D pattern of $-\rho \overline{u^{\prime} v^{\prime}}$ across the section. Under uniform flow conditions, the region of high Reynolds stress extends below the bank full level in both flumes. This is more pronounced in the LNEC flume. Since the aspect ratio $B_{m} / h_{b}$ and the velocity difference are comparable in both flumes, the sloping bank appears to be responsible for a higher turbulent diffusion at LNEC. Under non-uniform flow conditions, the cross-sectional pattern of Reynolds stress is highly altered by the timeaveraged transverse flow in the most downstream measuring sections of both flumes.

In the presence of a transverse flow towards the main channel $(N<1)$, different flow characteristics are observed depending upon whether the main channel is rectangular or trapezoidal. As mass exchange progressively increases at LMFA from $N=0.88$ to $N=0.64$, the high shear region is laterally stretched towards the main channel sidewall. The highest shear region remains located at the floodplain edge (see also Fig. 8), while a second local maximum detaches from the floodplain edge and is horizontally shifted towards the main channel sidewall (to $\approx y / B_{f}=1.1$ for $N=0.64$ ). The region of negative values of Reynolds stress associated with the local deficit in velocity is also displaced in the same direction. Simultaneously, the high shear region in the main channel is increasingly extended in the 
vertical direction from $N=0.88$ to $N=0.64$, highlighting the interaction between the transverse plunging flow and the shear-layer turbulence. At LNEC, as the transverse flow increases, the high shear region is first horizontally displaced towards the main channel ( $N=0.76$ ), and then vertically towards the sloping bank for $N=0.49$. With this latter flow, the farthest from equilibrium in Fig. 9, the high shear region is stretched towards the bottom of the slope by the transverse plunging flow and a second region of shear is produced near the centre of the main channel, as observed at LMFA.

In the case of a transverse flow towards the floodplains $(N>1)$, different flow conditions are also observed in both flumes, although the velocity difference, $U_{m}-U_{f}$, is comparable with $N=1.31$ and 1.25. The lateral Reynolds shear stresses are significantly higher at LNEC than at LMFA from $y / B_{f}=0.7$ to 1.1 (see also Fig. 8). This is particularly noticeable (i) below the bank full level, and (ii) within the near-surface layer on the floodplain. Since the lateral gradients $\partial U_{d} / \partial y$ shown in Fig. 5 are lower at LNEC than at LMFA, an increase of depth-averaged transverse eddy viscosity (see Equation 7 in section 3.2 ) is observed in this flume. Hence, in comparison with the vertical bank, the sloping bank enhances the shear-layer turbulence when the flow is uniform and when mass is transferred onto the floodplains.

\subsection{Momentum flux at floodplain edge}

As previously said, an accurate estimate of the transverse momentum flux at floodplain edge $\left(y / B_{f}=1\right)$ is required for $1 \mathrm{D}$ or $1 \mathrm{D}+$ modelling. In this section, we investigate this momentum flux at comparable distances $x / B_{f}$ in both flumes, i.e. 6.8 and 7.1 at LMFA and LNEC, respectively. Figure 10 shows the three contributions to this flux, namely the depth-averaged lateral Reynolds shear stress $T_{x y}$, the advective transport term $-\rho U_{d} V_{d}$ and the depth averaging of $-\rho \bar{u}\left(\bar{v}-V_{d}\right)$ (see Eqs. 4 and 5).

Because of the shallowness of the floodplain flow, the development of secondary currents is severely restricted. The dispersive term $-\rho \bar{u}\left(\bar{v}-V_{d}\right)$ is negligible compared to the other two terms. With higher values of velocity components $U_{d}$ and $V_{d}$ at LNEC, the variation range of $-\rho U_{d} V_{d}$ is larger at LNEC than LMFA, while the variation range of $T_{x y}$ is comparable in both flumes. With a transverse flow to the floodplain $(N>1), T_{x y}$ and $-\rho U_{d} V_{d}$ are positive and of the same order of magnitude in both flumes. With an opposite transverse flow $(N<1)$ : a) at LMFA, the advective momentum transport $-\rho U_{d} V_{d}$ increases with flow non-uniformity at the expense of the Reynolds stress $T_{x y}$, with the particular case 
"N $=0.84$ ", for which the total momentum flux is cancelled; b) at LNEC, the momentum flux is essentially advective.

Figure 11 shows the vertical distributions of lateral Reynolds shear stress $-\rho \overline{u^{\prime} v^{\prime}}$ and of flux $-\rho \overline{u v}$, at same locations as in Fig. 10. With $N<1$ at LNEC in Fig. 11(b), the shear stress $-\rho \overline{u^{\prime} v^{\prime}}$ is always negligible compared to $-\rho \overline{u v}$ at each elevation and for all cases. For $N>1$ in Fig. 11(a,b), the shear-layer turbulence seems to be enhanced by the sloping bank at LNEC, as the $N$-parameter is comparable in both flumes and the velocity difference is similar $(0.35 \mathrm{~m} / \mathrm{s}$ vs $0.33 \mathrm{~m} / \mathrm{s})$. Hence, the following conclusions may be drawn: (1) for an increasing transverse flow to the main channel, the advective momentum transport $\rho\left|U_{d} V_{d}\right|$ progressively rises at the expense of the shear-layer turbulence; (2) for a transverse flow to the floodplains, the two fluxes $-\rho U_{d} V_{d}$ and $T_{x y}$ are of the same sign and order of magnitude; (3) both $-\rho U_{d} V_{d}$ and $T_{x y}$ are strengthened by a sloping bank relative to a vertical one, irrespective of the lateral flow.

\subsection{Eddy viscosity at floodplain edge}

Given the qualitative link between the lateral shear stress $T_{x y}$ and gradients $\partial U_{d} / \partial y$ in section 4.6, a quantitative analysis of the relevance of the Boussinesq approach was performed at the floodplain edge $\left(y / B_{f}=1\right)$ and $x / B_{f}=6.8$ in the LMFA flume. Using a centred difference with $\Delta x=1 \mathrm{~cm}$ and $\Delta y=0.5 \mathrm{~cm}$, streamwise gradients $\partial V_{d} / \partial x$ were found to be one or two orders of magnitude lower than $\partial U_{d} / \partial y$ (same results holds for local gradients $\partial \bar{v} / \partial x$ and $\partial \bar{u} / \partial y)$. The definitions of the local and depth-averaged transverse eddy viscosities presented in Eqs. 6 and 7 were thus used. The distribution over the depth of the eddy viscosity, $\varepsilon_{x y}$, is shown in Fig. 12(a). It noticeably varies with the magnitude and direction of the time-averaged lateral flow. When mass is transferred to the floodplain ( $N=1.32)$, a strong increase of $\varepsilon_{x y}$ from bed to surface is observed. In contrast, with a mass transfer to the main channel, $\varepsilon_{x y}$ decreases when approaching the water surface for the case that is the furthest from equilibrium $(N=0.57)$. Hence, these profiles clearly highlight the interaction between the transverse flow and the shear-layer turbulence.

In this context, we tested the model of depth-averaged eddy viscosity developed by van Prooijen et al. (2005). The total eddy viscosity $\left.\varepsilon_{x y}\right|_{d}$ is the sum of the bed-induced eddy viscosity, $\left.\varepsilon_{x y}^{b}\right|_{d}$, and of the shear-layer-induced viscosity, $\left.\varepsilon_{x y}^{s}\right|_{d}$ : 


$$
\left.\varepsilon_{x y}\right|_{d}=\left.\varepsilon_{x y}^{b}\right|_{d}+\left.\varepsilon_{x y}^{s}\right|_{d}=\alpha h \sqrt{\frac{1}{8} f} U_{d}+\frac{h_{f}+h_{m}}{2 h} \beta^{2} \delta^{2}\left|\frac{\partial U_{d}}{\partial y}\right|
$$

The bed-induced turbulence is modelled by the Elder's model, in which $\alpha$ is a constant ( $\alpha \approx 0.1$ for wide open channel flows according to Rodi (1980)), and $f$ is the DarcyWeisbach friction coefficient. The shear-layer turbulence is modelled by a Prandtl's mixing length model with a length scale that is proportional to the mixing layer width, $\delta$ (defined here in Eq.9). With unbounded mixing layers, the proportionality constant $\beta$ is related to the spreading rate $d \delta / d x$ of the mixing layer, and ranges from 0.088 to 0.124 according to van Prooijen et al. (2005). In the LMFA flume, $d \delta / d x=0$ for the uniform flow at $x / B_{f}=6.8$, where the eddy viscosity model is estimated (see Fig. 6). Moreover, the mixing layer is shallow, and the geometry is compound. The $\beta$-parameter will thus be considered as a new constant, calibrated for the uniform flow $(\beta=0.026)$, which was then used to model the non-uniform cases.

Figure 12(b) shows the results at LMFA at $y / B_{f}=1$ and $x / B_{f}=6.8$. White and black circles are used for the total eddy viscosity $\left.\varepsilon_{x y}\right|_{d}$, and the shear-layer-induced viscosity, $\left.\varepsilon_{x y}^{s}\right|_{d}$ , respectively. The $f$-coefficient is estimated with a modified Colebrook formula (French 1985). Its value is approximately constant (0.021-0.022). This leads to very small variations in the bed-induced eddy viscosity, $\left.\varepsilon_{x y}^{b}\right|_{d}$, from 0.052 to 0.058 (difference between white and black circles in Fig. 12(b)).

Figure 12(b) shows that, with the $\beta$-parameter calibrated for uniform flow, accurate values of eddy viscosity $\left.\varepsilon_{x y}\right|_{d}$ are obtained for $N<1$. In contrast, $\left.\varepsilon_{x y}\right|_{d}$ is greatly underestimated for $N=1.32$. This flow is characterized by the highest shear-layer turbulence at LMFA, as shown in Fig. 10 (top plots). The underestimation of $\left.\varepsilon_{x y}\right|_{d}$ could thus be attributed to the limitations of the mixing length model. Firstly, this model assumes a local equilibrium between turbulence production and dissipation (e.g. Rodi 1980). Secondly, the local turbulent diffusion is exclusively related to the local gradients of time-averaged flow (Boussinesq approach), which can be erroneous if some structures are advected from upstream by the bulk flow. When mass is transferred to the floodplain, this advective transport of turbulent quantities can become important. In this case, Prandtl's model is not valid. In addition, considering the strong increase in eddy viscosity $\varepsilon_{x y}$ in the near-surface layer (Fig. 12(a)), the depth averaging of $\varepsilon_{x y}$ constitutes a rough approximation. 


\subsection{Momentum flux in the main channel}

The three contributions to transverse momentum flux, $-\rho U_{d} V_{d},-\left.\rho \bar{u}\left(\bar{v}-V_{d}\right)\right|_{d}$ and $T_{x y}$ were estimated in the main channel of the LMFA flume, in which the dispersive term of spanwise velocity $\bar{v}$ is important. The vertical distributions of velocity $\bar{v}$, flux $-\rho \bar{u} \bar{v}$ and Reynolds shear stress $-\rho \overline{u^{\prime} v^{\prime}}$ are shown in Fig. 13 at $x / B_{f}=5.6$, near the vertical interface at $y / B_{f}=1.01$, and near the centreline position at $y / B_{f}=1.28$. Table 2 shows at these two locations, the depth-averaged value of $-\rho \overline{u v}$, namely $M_{x y}$, the sum of terms $-\rho U_{d} V_{d}$ and $-\left.\rho \bar{u}\left(\bar{v}-V_{d}\right)\right|_{d}$, and shear $T_{x y}$.

At $y / B_{f}=1.01$, inside the shear-layer, the three fluxes can be of the same order of magnitude for the non-uniform cases (see Table 2). Figure 13(a) shows that the peak of lateral shear $-\rho \overline{u^{\prime} v^{\prime}}$ is located at the bank full level, irrespective of the value of the $N$-parameter. It is also shown that the variations in the $\bar{v}$-profiles are mostly located above the bank full level.

At $y / B_{f}=1.28$, outside the shear-layer, the momentum flux is essentially driven by the time-averaged flow for the non-uniform cases. In this case, the dispersive term $-\left.\rho \bar{u}\left(\bar{v}-V_{d}\right)\right|_{d}$ is lower than the advective transport of momentum $-\rho U_{d} V_{d}$, but of the same order of magnitude. Figure 13(b) shows that the overall shape of the $\bar{v}$-profiles is constant for all $N$-values, but with a lateral displacement towards the main channel sidewall when $N$ decreases. Table 2 also shows that the relative weight of the dispersive term of $\bar{v}$ decreases with $N$-parameter.

\section{Conclusions}

Turbulent non-uniform flows were experimentally investigated in two compound channels, with vertical and sloping banks in the main channel. A time-averaged transverse flow and an advective transport of momentum occurred until the most downstream measuring sections. The water depth reaches equilibrium more rapidly than the velocity difference between the sub-sections, and this latter can significantly vary for a given flow depth.

The advective transport of mass and momentum interacts with the shear-layer turbulence as follows:

(1) With a lateral flow to the main channel, the mixing layer and the shear-layer turbulence are laterally displaced in the same direction. The region of high values of lateral Reynolds stress $-\rho \overline{u^{\prime} v^{\prime}}$ is transversally stretched by the plunging flow into the 
main channel. As non-uniformity increases, the advective transport of momentum by the depth-averaged flow, $-\rho U_{d} V_{d}$, rises at the expense of the depth-averaged value of $-\rho \overline{u^{\prime} v^{\prime}}, T_{x y}$, at floodplain edge and in the main channel.

(2) With a lateral flow to the floodplains, the shear layer turbulence widely extends on the floodplains, with higher values of $-\rho \overline{u^{\prime} v^{\prime}}$ and of transverse eddy viscosity $\varepsilon_{x y}$ in the near-surface layer. Both the flux $-\rho U_{d} V_{d}$ and shear stress $T_{x y}$ are of the same order of magnitude.

The shear-layer turbulence and the flux $-\rho U_{d} V_{d}$ are enhanced by the sloping bank, relative to the vertical bank. With this latter, the dispersive term of spanwise velocity, $-\left.\rho \bar{u}\left(\bar{v}-V_{d}\right)\right|_{d}$, can be of the same order of magnitude as $-\rho U_{d} V_{d}$, and is dependent on the flow direction. As a result, a 2D-depth-averaged model that does not account for the vertical dispersion of velocity $\bar{v}$, or a depth-averaged model that is based on uniform flow hypotheses $\left(\partial h / \partial x=0\right.$ and $\left.V_{d}=0\right)$ may poorly reproduce the actual transverse momentum flux.

The two data sets showed that the Boussinesq approach was qualitatively appropriate for non-uniforms flows. Using the depth-averaged model of eddy viscosity developed by van Prooijen et al. (2005) for uniform flows, we found that the model was still valid with a lateral flow to the main channel. In contrast, it significantly underestimates the eddy viscosity with an opposite lateral flow, i.e. when the horizontal vortices are widely extended on the floodplains. Both the Boussinesq approach and the mixing length models are not valid in this case.

An excess (resp. a deficit) in floodplain discharge is observed in a compound channel with converging (resp. diverging) floodplains. As a result, a part of the physical processes depicted in this paper, notably the interaction between time-averaged transverse flow and shear-layer turbulence, may be valid for non-prismatic geometries.

Since these results were obtained with a single relative flow depth, $D_{r}=0.3$ under uniform flow conditions, this work will be continued by an investigation of the shallowness effect on the turbulent non-uniform flows.

\section{Acknowledgements}

Travel costs of J. Leal, J. Fernandes and S. Proust were supported by a Hubert Curien Project Pessoa, funded by EGIDE, France, and by FCT, Portugal. The authors are grateful to Fabien Thollet, Mickaël Lagouy and Pedro Duarte, for their assistance during the experiments. They are also grateful to Roger Bettess for his corrections. 


\section{Notation}

Superscript $u$ refers to uniform flows

Subscripts $m$ and $f$ refer to main channel and floodplain, respectively

Subscript $d$ refers to a depth averaging

$518 h_{f}, h_{m} \quad=$ mean water depths on the floodplain and in the main channel [m] $=$ depth-averaged value of transverse momentum flux $-\rho \bar{u} \bar{v}\left[\mathrm{~N} / \mathrm{m}^{2}\right]$

\section{References}

Bousmar, D., Zech, Y. (1999). Momentum transfer for practical flow computation. J. Hydraulic Eng. 125(7), 696-706.

Bousmar, D., Proust, S. and Zech, Y. (2006). Experiments on the flow in a enlarging compound channel. In Proc. of the int. conf. on fluvial hydraulics, River flow 2006 , vol. 1, pp. 323-332. 6-8 September, Lisbon, Portugal: Ferreira, Alves, Leal and Cardoso (eds.).

Bousmar, D., Wilkin, N., Jacquemart, J.H., Zech, Y. (2004). Overbank flow in symmetrically narrowing floodplains. J. Hydraulic Eng. 130 (4), 305-312.

Bousmar, D., Riviere, N., Proust, S., Paquier, A., Morel, R. Zech, Y. (2005) Upstream discharge distribution in compound-channel flumes. J. Hydraulic Eng. 131 (5), 408412.

Chanson, H., Trevethan, M., C Koch. Discussion of "Turbulence Measurements with Acoustic Doppler Velocimeters" by Carlos M. Garcia, Mariano I. Cantero, Yarko Niño, and Marcelo H. Garcia. J. Hydraulic Eng. 133 (2007) 1286-9.

French, R.H. (1985). Open-channel hydraulics, McGraw-Hill, New York.

Goring, D. G., Nikora, V. I. (2002). Despiking acoustic doppler velocimeter data. J. Hydraulic Eng.128(1), 117-126.

Ikeda, McEwan (2009). Flow and sediment transport in compound channels. IAHR Monograph series, $333 \mathrm{p}$.

Jirka, G.H. (2001). Large scale flow structures and mixing processes in shallow flows. $J$. Hydraulic Res. 39 (6), 567-573. 
Kara, S., Stoesser, T., Sturm, T. W. (2012). Turbulence statistics in compound channels with deep and shallow overbank flows. J. Hydraulic Res. 50(5), 482-493.

Knight, D.W., Shiono, K. (1990). Turbulence measurements in a shear layer region of a compound channel. J. Hydraulic Res. 28 (2), 175-194.

McLelland, S. J., Nicholas, A. P (2000). A new method for evaluating errors in highfrequency adv measurements. Hydrological Processes 14, 351-366.

Nezu, I., Onitsuka, K., Iketani, K. (1999). Coherent horizontal vortices in compound open channel flows. In Hydraulic modelling (ed. I. W. Seo V. P. Singh \& J. H. Sonu), pp. 1732. Water Resources Publications, Colorado, USA.

Peltier, Y., Proust, S., Rivière, N., Paquier, A., Shiono, K (2013a). Turbulent flows in straight compound open-channel with a transverse embankment on the floodplain. J. Hydraulic Res., iFirst, 1-13, DOI:10.1080/00221686.2013.

Peltier, Y., Rivière, N., Proust, S., Mignot E., Paquier A., Shiono, K. (2013b). Estimation of the error on the mean velocity and on the Reynolds stress due to a misoriented ADV probe in the horizontal plane: case of experiments in a compound open-channel. Under review to Flow Meas. And Inst.

Pope, S. (2000). Turbulent flows. Cambridge University Press, Cambridge UK.

van Prooijen, B.C., Battjes, J.A., Uijttewaal, W.S.J. (2005). Momentum exchange in straight uniform compound channel flow. J. Hydraulic Eng.131 (3), 175-183.

Proust, S., Riviere, N., Bousmar, D., Paquier, A., Zech, Y., Morel, R. (2006). Flow in compound channel with abrupt floodplain contraction. J. Hydraulic Eng. 132 (9), 958970.

Proust, S., Bousmar, D., Rivire, N., Paquier, A., Zech, Y. (2009). Non-uniform flow in compound channel: a 1D-method for assessing water level and discharge distribution. Water Resources Res. 45 (W12411), 1-16.

Proust, S., Bousmar, D., Rivière, N., Paquier, A., Zech, Y. (2010). Energy losses in compound open channels. Adv. Water Res. 33 (1), 1-16.

Rodi, W. (1980). Turbulence models and their application in hydraulics: a state of the art review, IAHR book publication, Delft.

Roy, A. G., Biron, P., de Serres, B. (1996). On the necessity of applying a rotation to instantaneous velocity measurements in river flows. Earth Surface Processes and Landforms, 21(9), 817-827.

Sellin, R.H.J. (1964). A laboratory investigation into the interaction between the flow in the channel of a river and that over its flood plain. La Houille Blanche (7), 793-802.

Shiono, K. and Knight, D.W. (1991). Turbulent open channel flows with variable depth across the channel. J. Fluid Mech. 222, 617-646.

Tominaga, A. and Nezu, I. (1991). Turbulent structure in compound open-channel flows. $J$. Hydraulic Eng. 117 (1), 21-41

Vermaas, D.A., Uijttewaal, W.S.J., Hoitink, A.J.F. (2011). Lateral transfer of streamwise momentum caused by a roughness transition across a shallow channel. Water Resources Res. 47 (W02530), 1-12. 
Table 1 Flow conditions

\begin{tabular}{|c|c|c|c|c|c|c|c|c|c|}
\hline & \multicolumn{2}{|c|}{ Inflow $(x=0)$} & \multicolumn{7}{|c|}{${ }^{\mathrm{b}}$ Most upstream measuring section } \\
\hline & $\begin{array}{l}{ }^{\mathrm{a}} \Delta Q_{f} \\
{[\%]}\end{array}$ & $\begin{array}{l}Q_{f} / Q \\
{[\%]}\end{array}$ & $\begin{array}{l}N \\
{[-]}\end{array}$ & $\begin{array}{l}D_{r} \\
{[-]}\end{array}$ & $\begin{array}{l}h_{f} \\
{[\mathrm{~mm}]}\end{array}$ & $\begin{array}{l}U_{f} \\
{[\mathrm{~cm} / \mathrm{s}]}\end{array}$ & $\begin{array}{l}\mathrm{F}_{f} \\
{[-]}\end{array}$ & $\begin{array}{l}U_{m} \\
{[\mathrm{~cm} / \mathrm{s}]}\end{array}$ & $\begin{array}{l}\mathrm{F}_{m} \\
{[-]}\end{array}$ \\
\hline \multirow{5}{*}{ 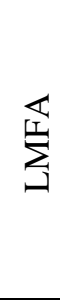 } & -19 & 20.6 & 1.42 & 0.286 & 21.2 & 31.0 & 0.69 & 70.0 & 0.94 \\
\hline & 0 & 25.4 & 1.00 & 0.303 & 23.0 & 33.3 & 0.71 & 60.7 & 0.81 \\
\hline & +19 & 30.2 & 0.66 & 0.311 & 24.0 & 38.5 & 0.80 & 56.6 & 0.75 \\
\hline & +38 & 35.0 & 0.45 & 0.324 & 25.4 & 40.7 & 0.83 & 53.0 & 0.70 \\
\hline & +53 & 38.8 & 0.32 & 0.329 & 25.9 & 42.3 & 0.85 & 51.0 & 0.67 \\
\hline \multirow{4}{*}{ 岌 } & -19 & 26.6 & 1.54 & 0.275 & 38.0 & 41.8 & 0.70 & 79.6 & 0.78 \\
\hline & 0 & 32.8 & 1.00 & 0.285 & 40.1 & 47.9 & 0.79 & 72.5 & 0.70 \\
\hline & +19 & 39.0 & 0.52 & 0.297 & 42.2 & 53.0 & 0.85 & 65.7 & 0.63 \\
\hline & +38 & 45.2 & 0.00 & 0.304 & 43.8 & 58.6 & 0.92 & 58.6 & 0.56 \\
\hline
\end{tabular}

599

${ }^{\mathrm{a}}$ Imbalance in floodplain inflow, relative to uniform flow (see Eq. 1)

600

${ }^{\mathrm{b}} x=2.5 \mathrm{~m}$ at LMFA, $x=1.1 \mathrm{~m}$ at LNEC

601

602 Table 2 Transverse momentum flux in the main channel at LMFA, $x / B_{f}=5.6$.

\begin{tabular}{cccccc}
\hline$y / B_{f}$ & $N$ & $M_{x y}$ & $-\rho U_{d} V_{d}$ & $-\rho U\left(V-V_{d}\right) I_{d}$ & $T_{x y}$ \\
{$[-]$} & {$[-]$} & {$[\mathrm{Pa}]$} & {$[\mathrm{Pa}]$} & {$[\mathrm{Pa}]$} & {$[\mathrm{Pa}]$} \\
\hline \multirow{4}{*}{1.01} & 1.33 & 4.2 & 4.2 & 0.0 & 0.7 \\
& 1 & 0.0 & 0.0 & 0.0 & 0.6 \\
& 0.79 & 0.0 & -0.1 & 0.1 & 0.3 \\
& 0.64 & 0.0 & -0.2 & 0.2 & 0.2 \\
& 0.50 & -1.1 & -1.2 & 0.1 & 0.1 \\
\hline \multirow{4}{*}{1.28} & 1.33 & 1.0 & 1.6 & -0.6 & 0.0 \\
& 0.79 & -0.5 & 0.0 & -0.5 & 0.1 \\
& 0.64 & -2.6 & -0.3 & -0.3 & 0.0 \\
& 0.50 & -2.8 & -2.6 & -0.3 & 0.0 \\
& & & & -0.2 & 0.0 \\
\hline
\end{tabular}


(a)

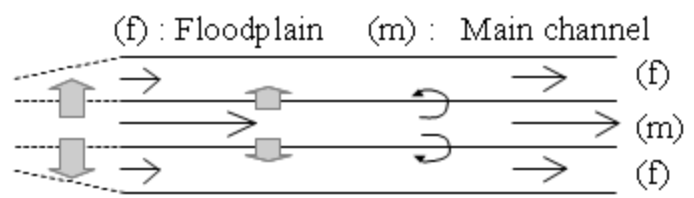

(b)
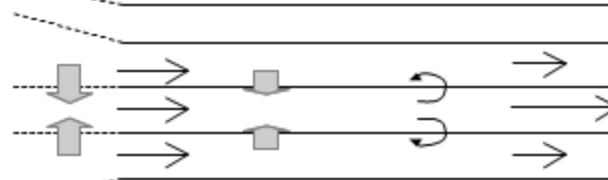

(c)
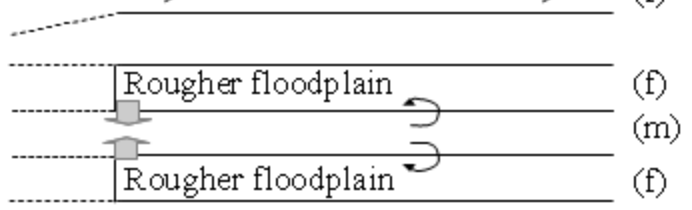

607

$\Rightarrow$ Time-averaged transverse flow

Shear-layer turbulence

$\longrightarrow$ Streamwise velocity

Figure 1 Various flow conditions for natural compound channels: (a) diverging or (b) converging floodplains upstream from a prismatic reach, (c) prismatic reach with a longitudinal increase in roughness on the floodplains

611

612

613

614

615

616

617

618

619 
LMFA flume
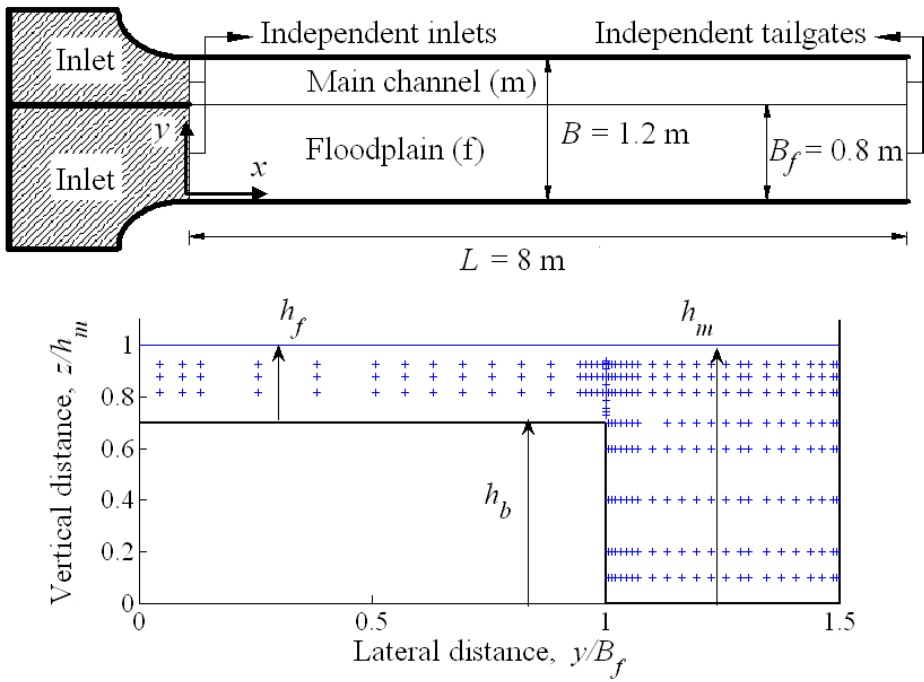

\section{LNEC flume}
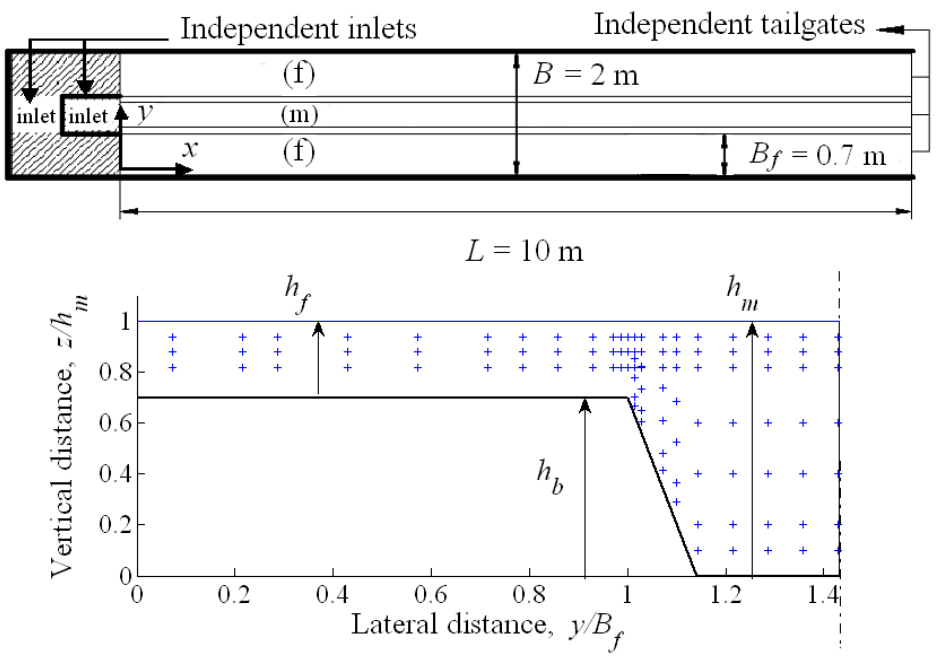

Figure 2 Schematic top view and cross-section of the two flumes (markers '+': ADV measuring grid) 
LMFA -...-..- LNEC — Floodplain inflow:

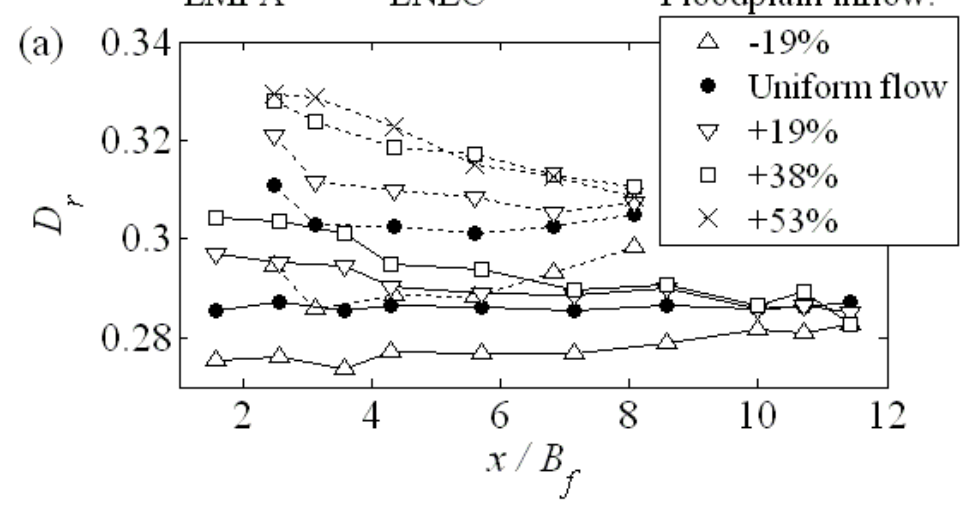

(b)

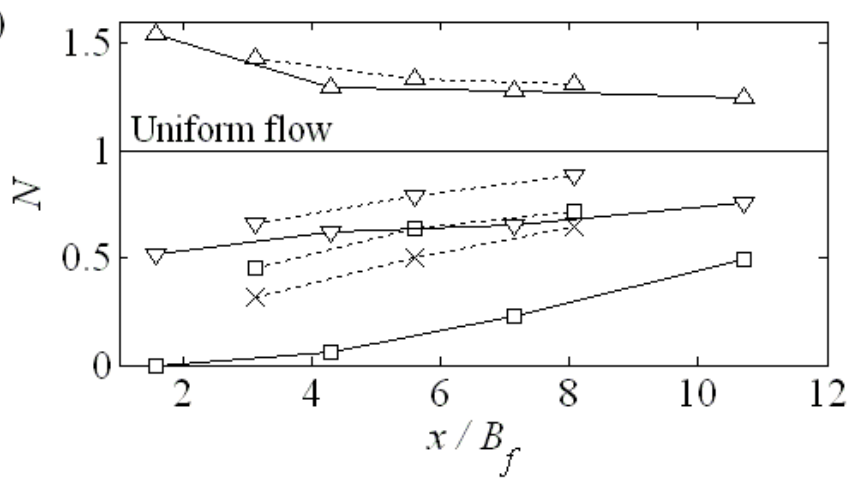

629

Figure 3 (a) Relative flow depth, $D_{r}$, and (b) velocity difference between sub-sections relative 630 to uniform flow conditions, $N=\left(U_{m}-U_{f}\right) /\left(U_{m}^{u}-U_{f}^{u}\right)$, against downstream distance, $x / B_{f}$ 


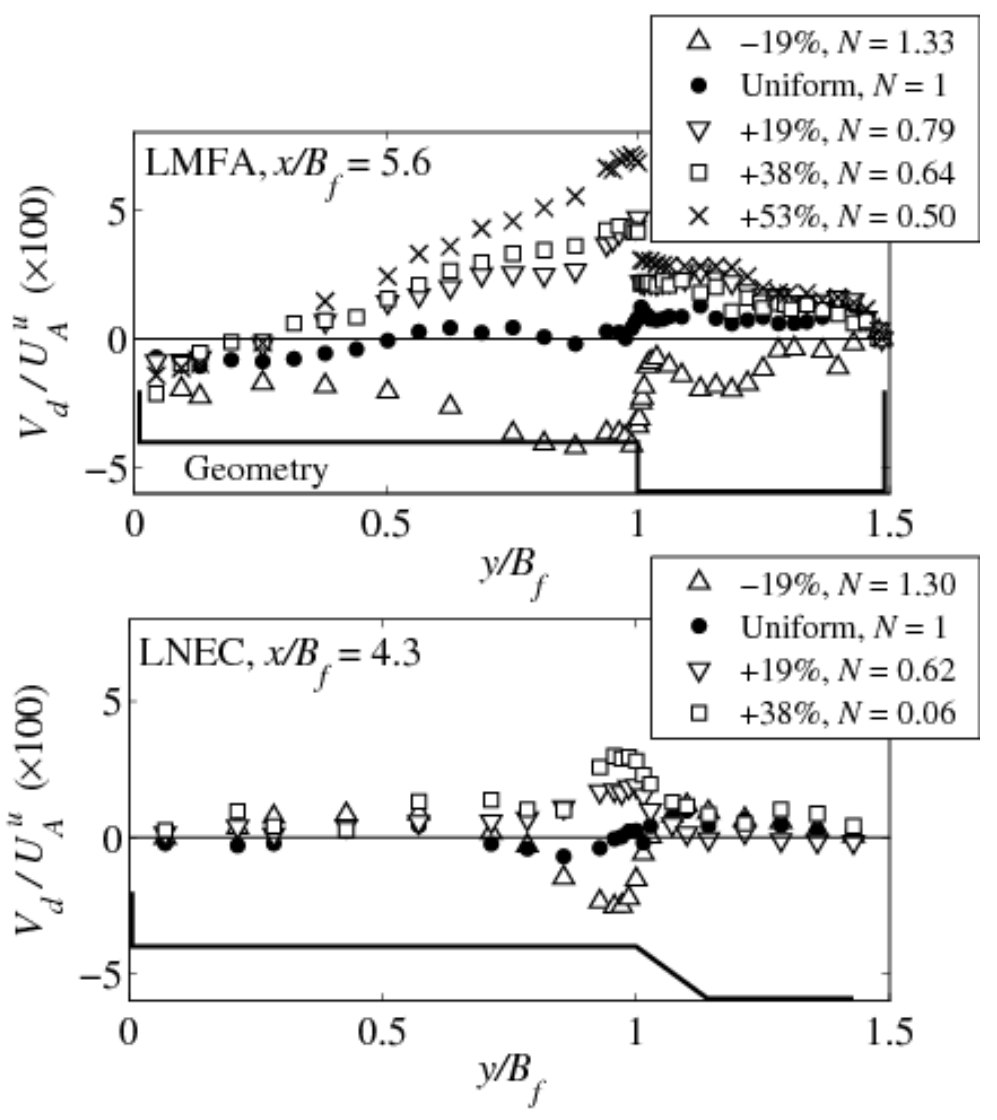

632 Figure 4 Lateral distribution of depth-averaged spanwise velocity, $V_{d}$, scaled by bulk velocity, $633 U_{A}^{u}$, for various $N$-parameters.

634 

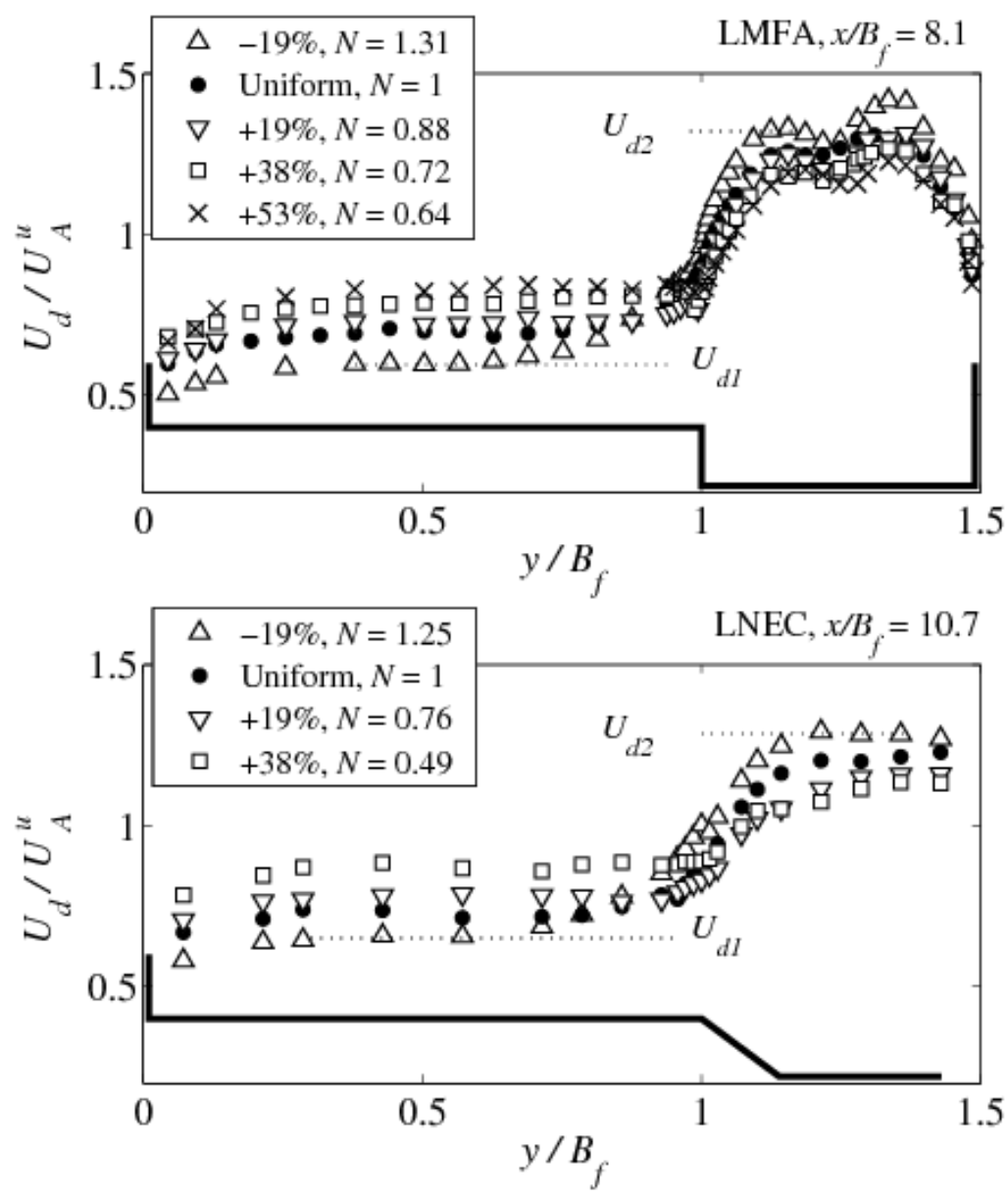

635

636 Figure 5 Lateral distribution of depth-averaged streamwise velocity, $U_{d}$, scaled by $U_{A}^{u}$ 

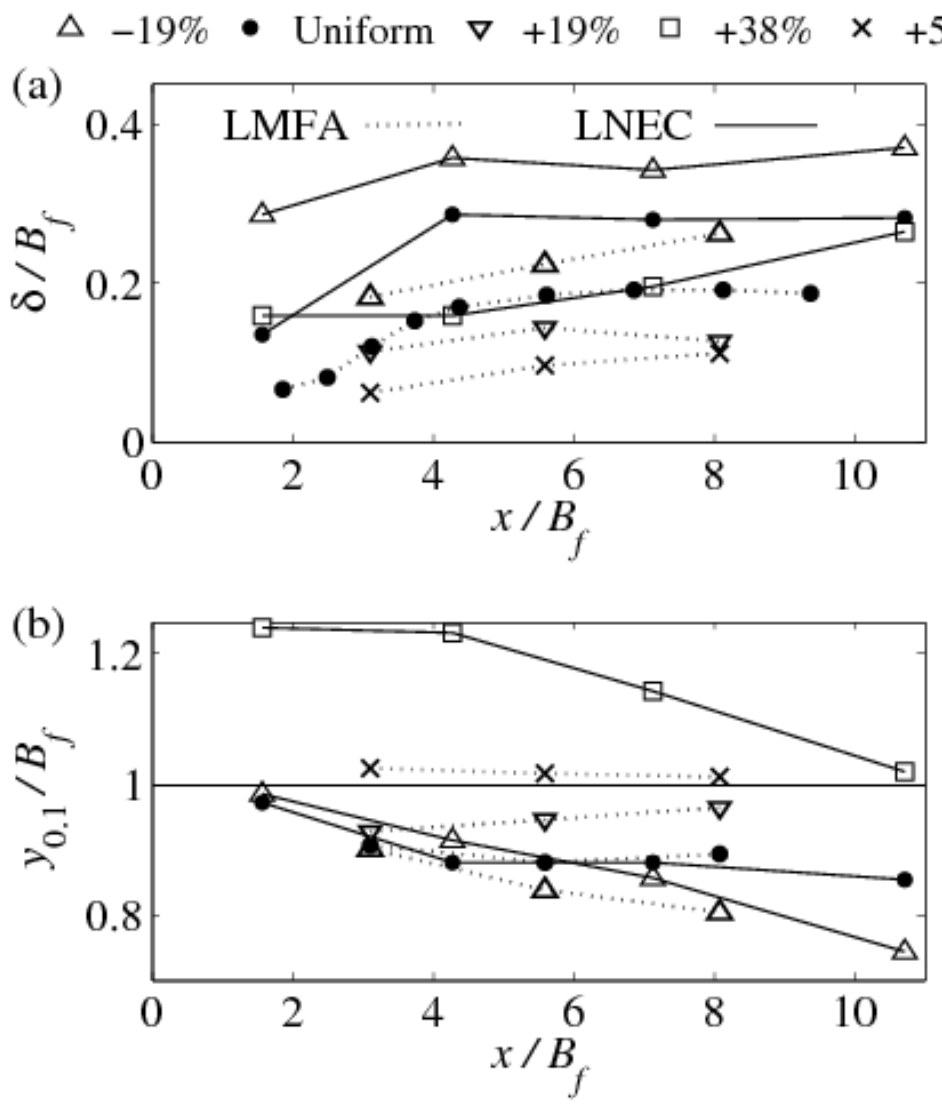

639 Figure 6 Longitudinal profile of (a) mixing layer width, $\delta$, and (b) lateral boundary, $y_{0.1}$ (see 640

641 Eq. 9), scaled by $B_{f}$. 
(a)
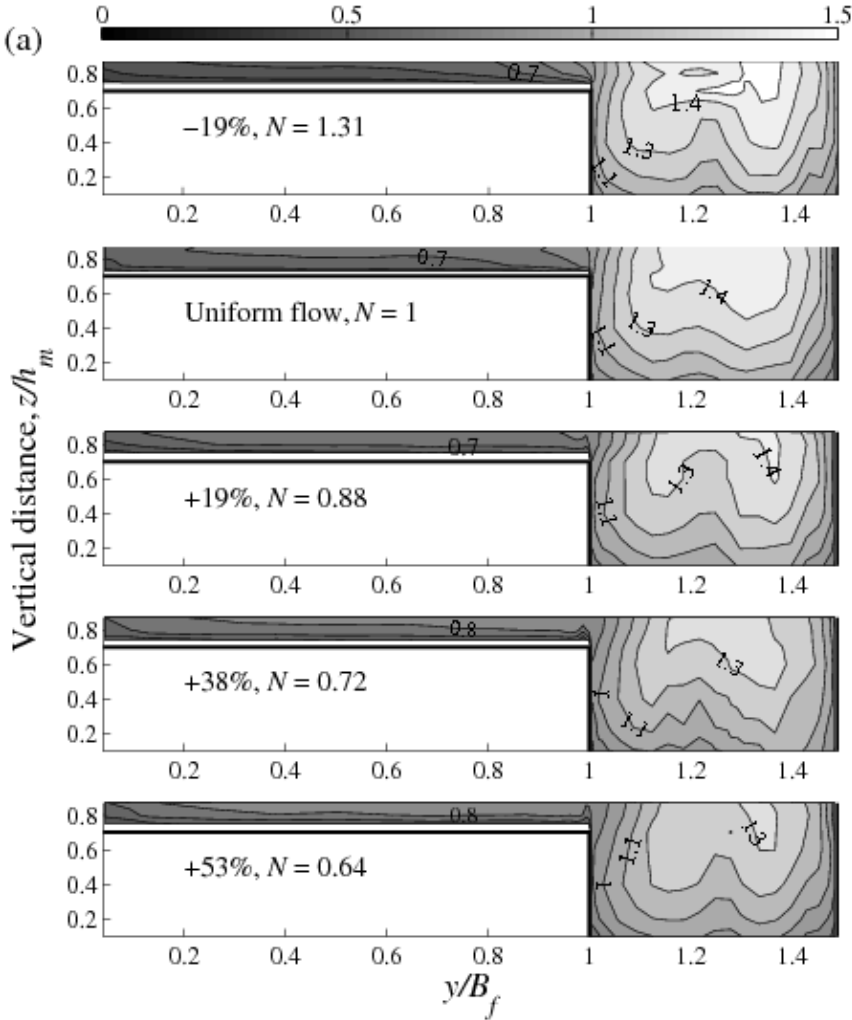

642

(b)
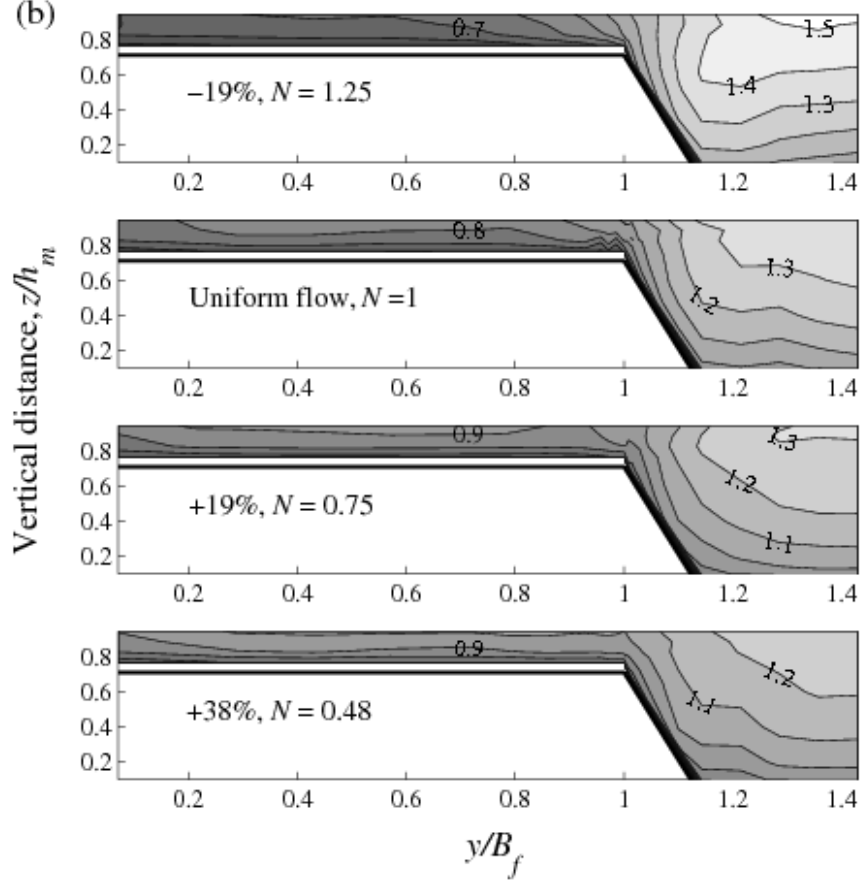

643

644

645 646
Figure 7 Time-averaged streamwise velocity, $\bar{u}$, scaled by $U_{A}^{u}$, for various $N$-parameters: (a) LMFA, $x / B_{f}=8.1$; and (b) LNEC, $x / B_{f}=10.7$ 

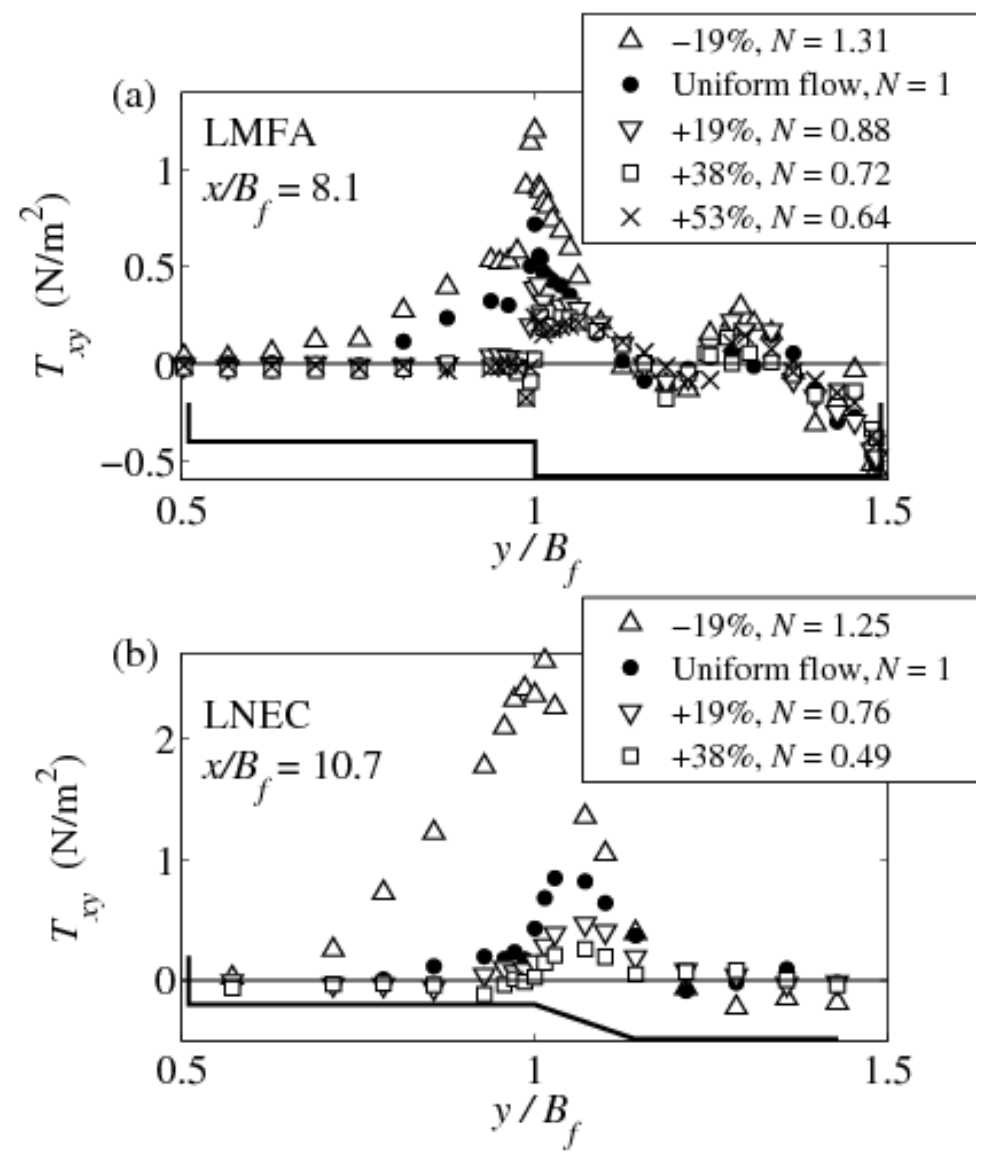

647

648 Figure 8 Depth-averaged lateral Reynolds shear stress, $T_{x y}$, against lateral distance, $y / B_{f}$. 

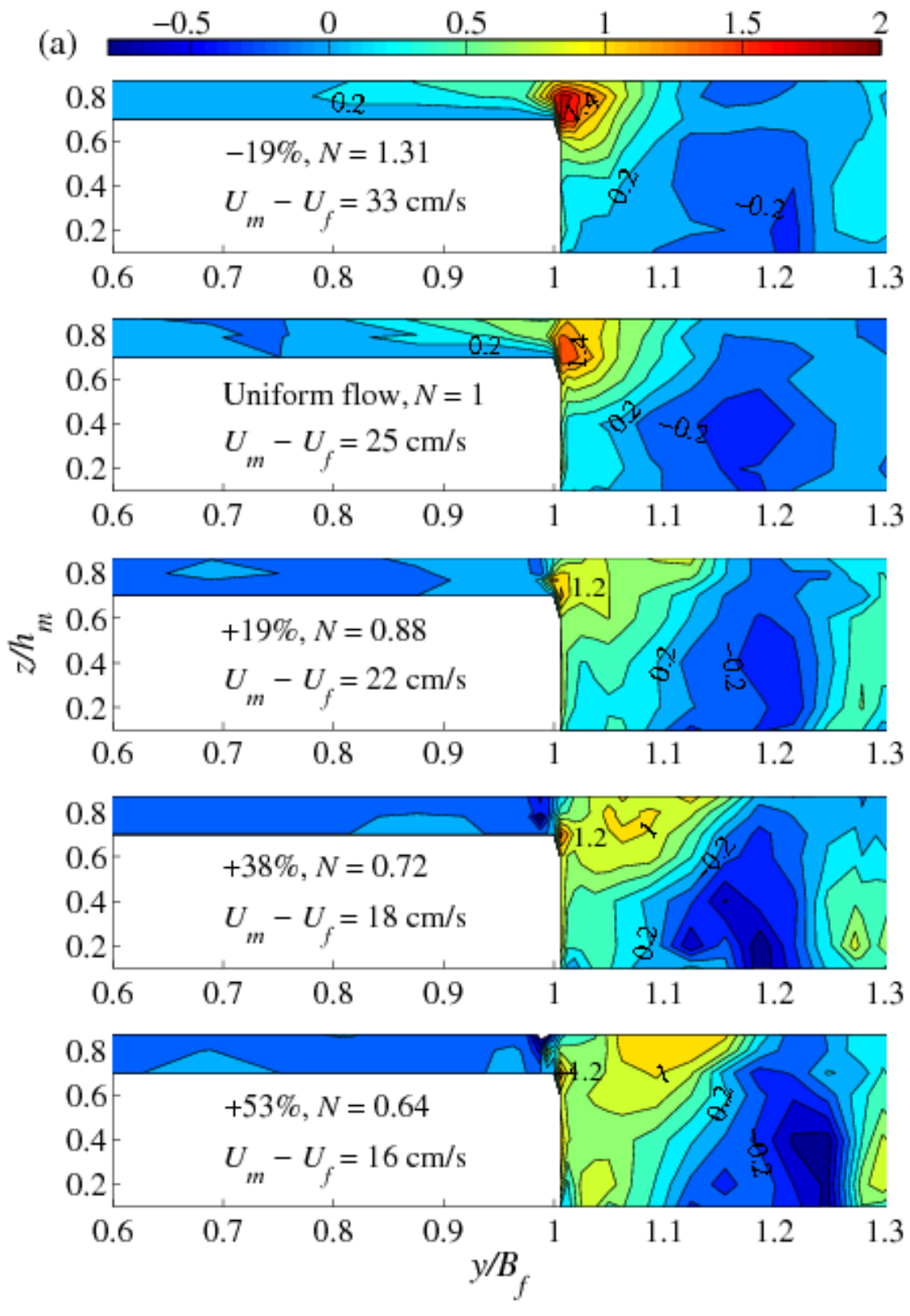
(b)
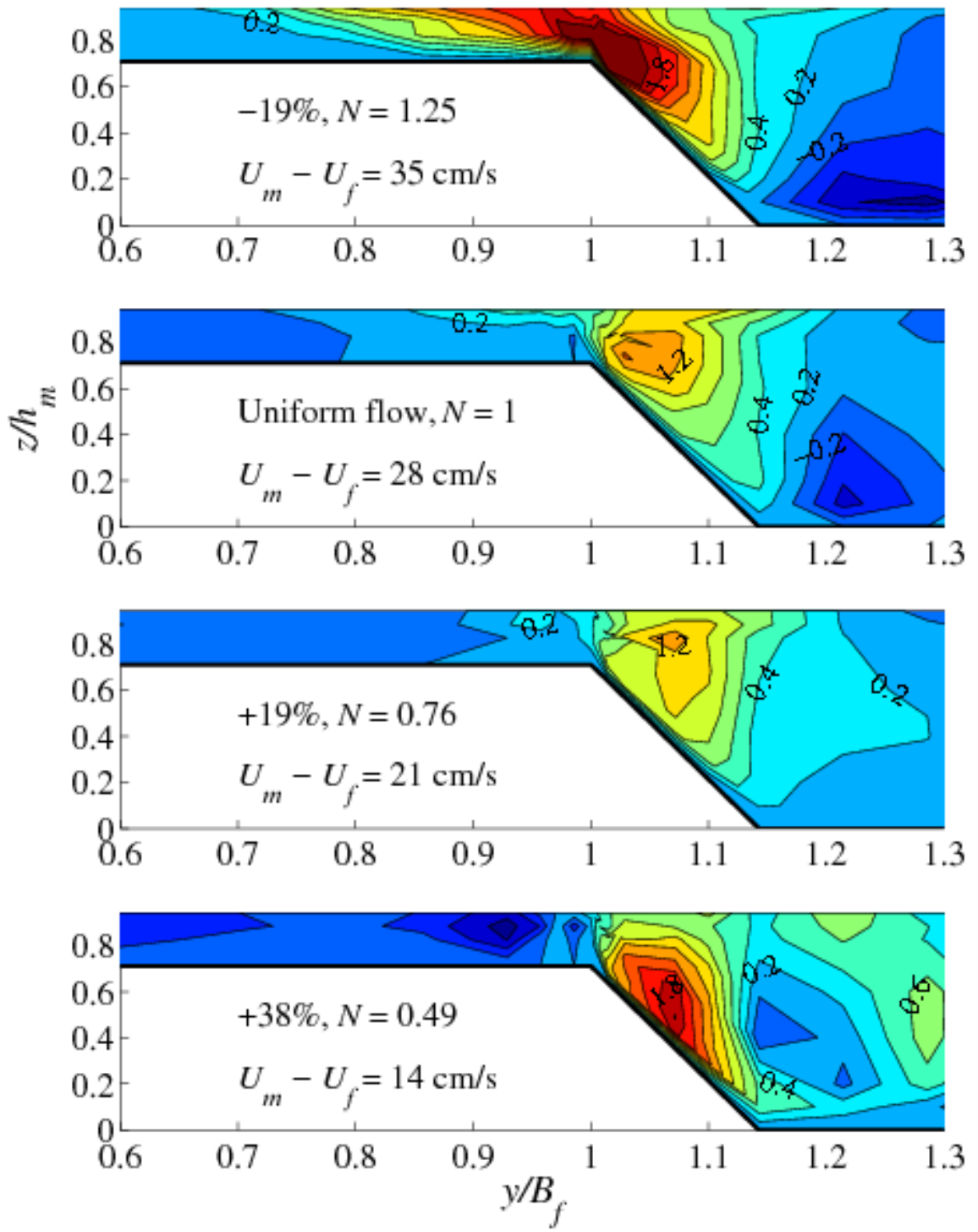

650

651 Figure 9 Normalized lateral Reynolds shear stress, $-\overline{u^{\prime} v^{\prime}} /\left(U_{m}-U_{f}\right)^{2}(\times 100)$. (a) LMFA,

$652 x / B_{f}=8.1 ;$ and $(\mathrm{b})$ LNEC, $x / B_{f}=10.7$ 
○ Reynolds stress, $T_{x y} \quad \boldsymbol{\Delta}-\rho U_{d} V_{d} \Delta$ Depth averaging of $-\rho \bar{u}\left(\bar{v}-V_{d}\right)$

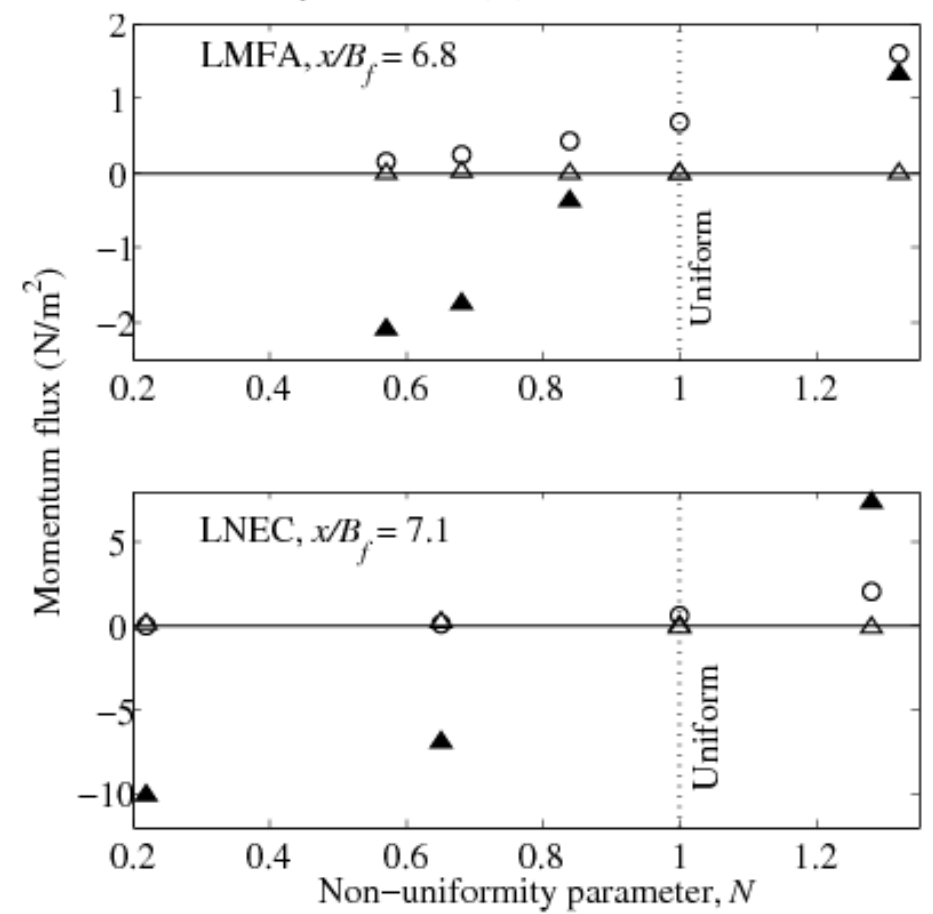

654

655

Figure 10 The three contributions to transverse momentum flux at floodplain edge $\left(y / B_{f}=1\right)$ 
657
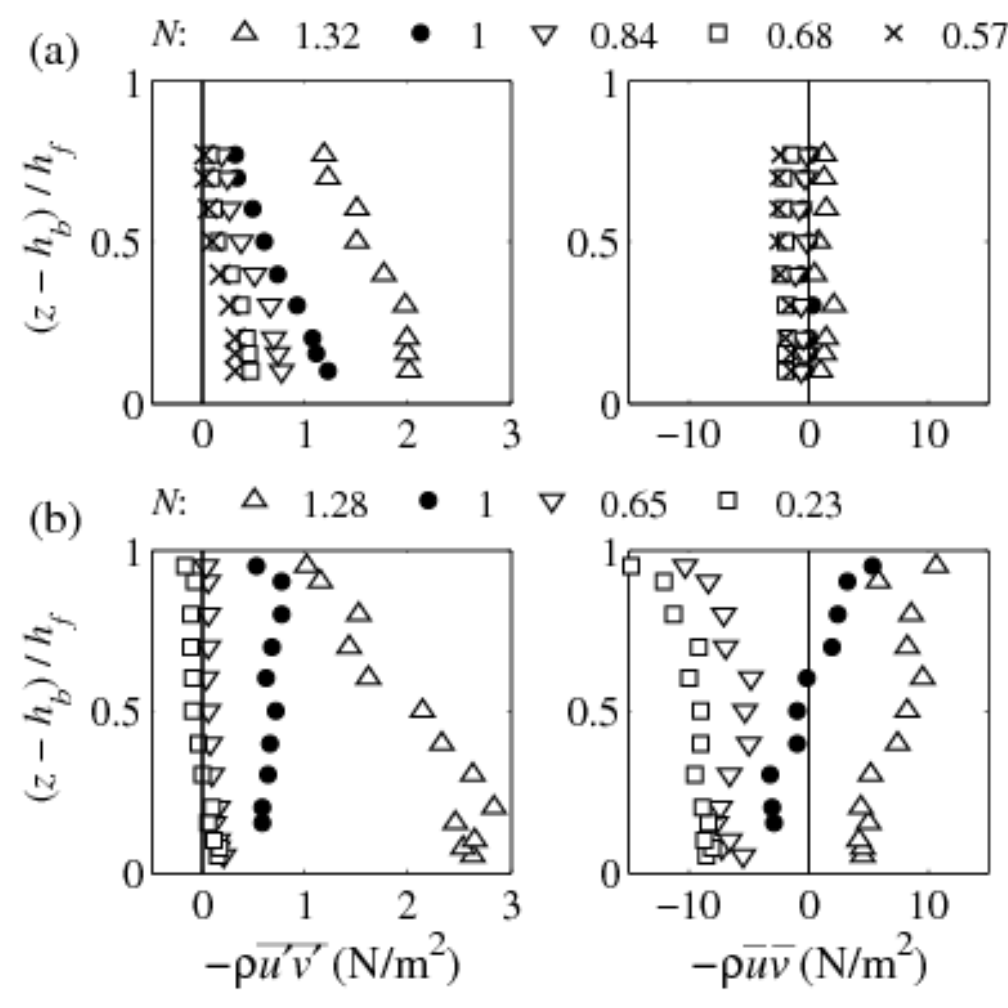

658

659 Figure 11 Vertical distribution of lateral Reynolds shear stress $-\rho \overline{u^{\prime} v^{\prime}}$ and of momentum

660 flux $-\rho \overline{u v}$ at floodplain edge $\left(y / B_{f}=1\right)$. (a) LMFA, $x / B_{f}=6.8$; (b) LNEC, $x / B_{f}=7.1$ 


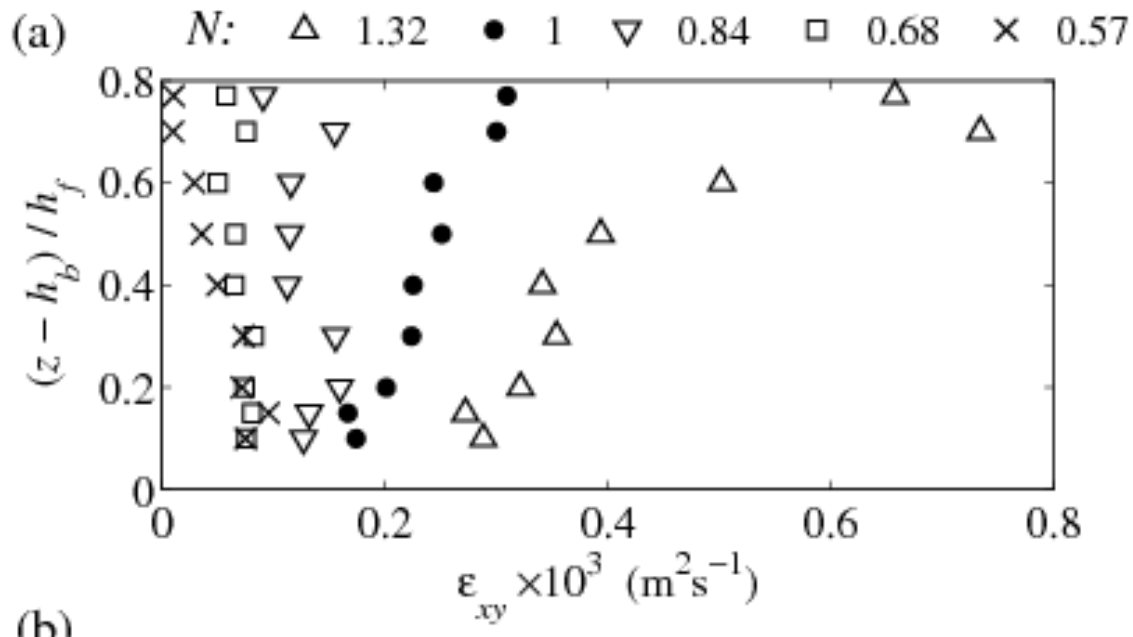

(b)

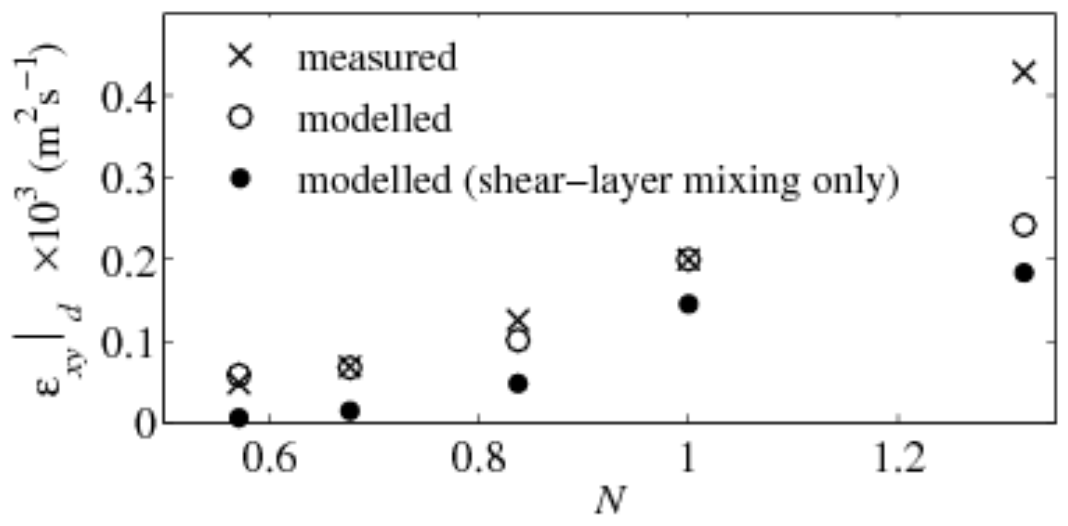

662 Figure 12 (a) Vertical distribution of eddy viscosity, $\varepsilon_{x y}$, and (b) depth-averaged eddy viscosity, $\left.\varepsilon_{x y}\right|_{d}$, measured and modelled data (see Eq. 10). LMFA flume, floodplain edge

664 $\left(y / B_{f}=1\right), x / B_{f}=6.8$.

665

666 

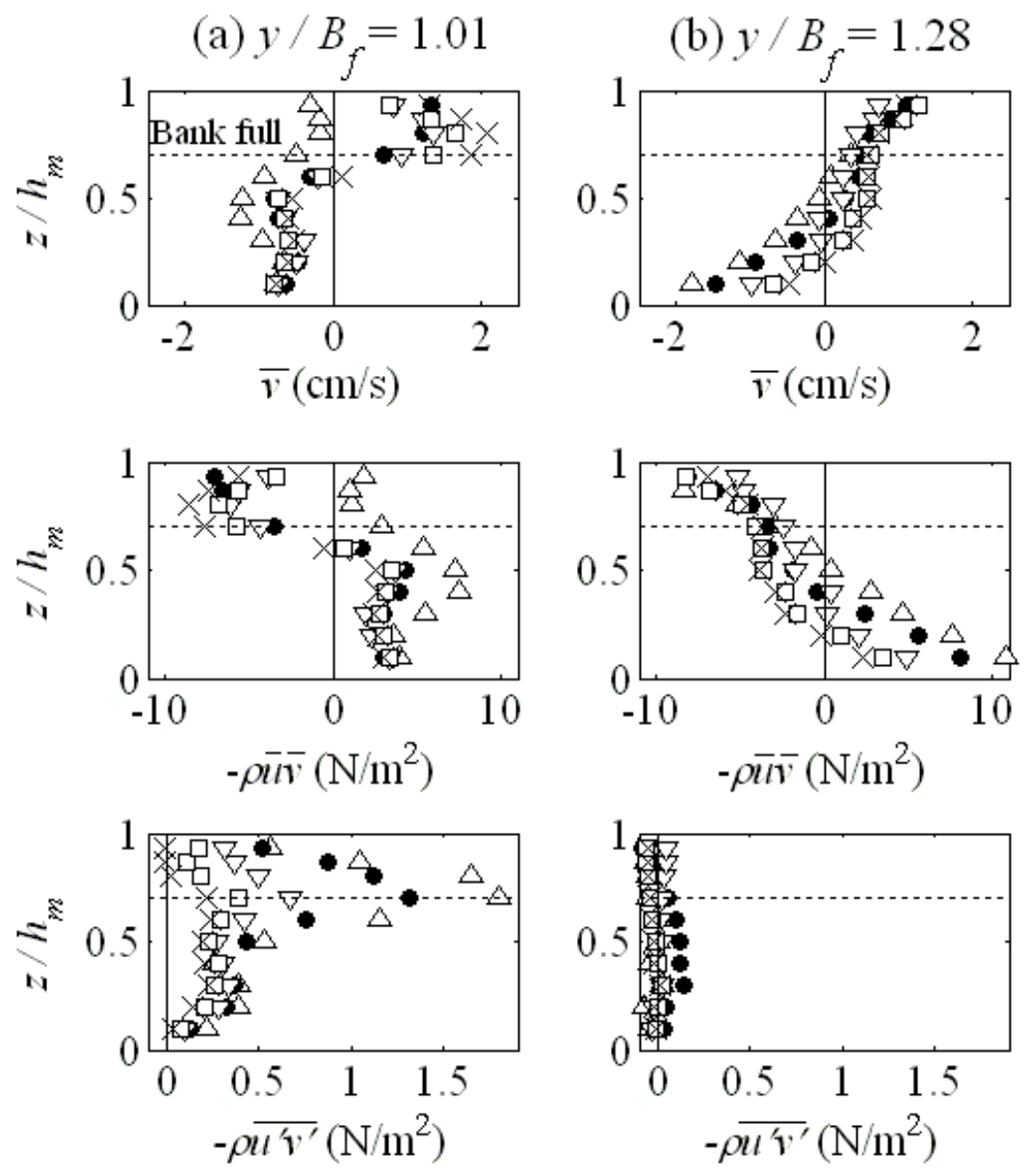

667

$$
N: \Delta 1.33 \cdot 1 \quad \nabla \quad 0.79 \quad \square \quad 0.64 \times 0.50
$$

668 Figure 13 Vertical distribution of spanwise velocity $\bar{v}$, flux $-\rho \overline{u v}$ and Reynolds shear stress

$669-\rho \overline{u^{\prime} v^{\prime}}$, in the main channel of LMFA flume, $x / B_{f}=5.6$

670 